\title{
DESVELANDO O CAMPO DA ESTRATÉGIA COMO PRÁTICA E SUAS RELAÇÕES
}

\section{RESUMO}

O objetivo deste estudo é analisar a produção acadêmica sobre estratégia como prática (strategy as practice), buscando compreender o perfil e tendências do campo a partir do texto seminal de Whittington, R., Strategy as Practice. Para tanto, 103 artigos presentes na base de dados Web of Science foram analisados por meio das técnicas bibliometria (quantificação e caracterização da produção científica) e sociometria (representação gráfica de redes e verificação dos pontos de inflexão), com auxílio dos softwares CiteSpace e NVivo 10. Em seguida foram discutidos os textos considerados 'turning points' e referências centrais na análise de redes. Os resultados apontam que a estratégia como prática é centrada em textos com ênfase nas categorias analíticas 'poder' e 'instituições' e nos pontos de inflexão é verificada a importância da 'virada narrativa', bem como dos 'discursos estratégicos' e do 'sensemaking'.

Palavras-chave: Estratégia como Prática, Bibliometria, Sociometria, Produção Científica.

\section{UNVEILING THE STRATEGY AS PRACTICE FIELD AND ITS RELATIONS}

\begin{abstract}
The objective of this study is to analyze the academic literature on strategy as practice trying to understand the profile and trends of the area from the seminal text Strategy as Practice, by Whittington, R. For this, 103 articles present in the Web of Science Core Collection were analyzed through bibliometric techniques (quantification and characterization of scientific production) and sociometry (graphical representation of network, verification of turning points), operationalized through CiteSpace software and NVivo 10 from which was made a discussion on the texts considered 'turning points' and central references in network analysis. The results show that the strategy as practice is centered in texts with emphasis on analytical categories 'power' and 'institutions', and in the turning points analysis is verified the importance of the 'narrative turn', as well as the strategic discourse and sensemaking.
\end{abstract}

Keywords: Strategy as Practice, Bibliometrics, Sociometrics, Scientific Production. 


\section{REVELANDO EL CAMPO DE LA ESTRATEGIA COMO UNA PRÁCTICA Y SUS RELACIONES}

\section{RESUMEN}

El objetivo de este estudio es analizar la investigación académica sobre la estrategia como la práctica (estrategia de la práctica), tratando de conocer el perfil y las tendencias en el campo del texto seminal Whittington, R., Estrategia de Prácticas. Por lo tanto, los artículos 103 presentes en la Web de la base de datos Science se analizaron a través de técnicas bibliométricas (cuantificación y caracterización de la producción científica) y la sociometría (representación gráfica de las redes y la verificación de los puntos de inflexión), con la ayuda de software NVivo y CiteSpace 10. A continuación examinó los textos considerados 'puntos de inflexión' y las referencias básicas en el análisis de redes. Los resultados indican que la estrategia como práctica se centra en los textos con énfasis en categorías analíticas 'poder' y 'instituciones' y puntos de inflexión se verifica la importancia del «giro narrativo" y el "discurso estratégico 'y' sensemaking '.

Palabras clave: Estrategia y Práctica, Bibliometría, Sociometry, la producción Científica.

Luís Fernando Silva Andrade ${ }^{1}$

André Luiz de Paiva ${ }^{2}$ Valderí de Castro Alcântara ${ }^{3}$ Mozar José Brito ${ }^{4}$

\footnotetext{
${ }^{1}$ Doutorando em Administração pela Universidade Federal de Lavras - UFLA. Brasil. E-mail: andradelfs@gmail.com

${ }^{2}$ Mestrando em Administração pela Universidade Federal de Lavras - UFLA. Brasil. E-mail: andrepaiva2@gmail.com

3 Doutorando em Administração pela Universidade Federal de Lavras - UFLA. Brasil. E-mail: valderi.alcantara@ posgrad.ufla.br

${ }^{4}$ Doutor em Administração pela Universidade de São Paulo - USP. Professor da Universidade Federal de Lavras UFLA. Brasil. E-mail: mozarbrito@gmail.com
} 


\section{INTRODUÇÃ̃O}

A perspectiva da Estratégia como Prática (Strategy as Practice - SAP) é um campo de estudos relativamente recente no qual se considera que o fenômeno da estratégia organizacional não é mais algo que as organizações possuem, mas sim aquilo que as pessoas fazem (Jarzabkowski, Balogun, \& Seidl, 2007). Na SAP, existe uma diversidade de autores e temáticas trabalhadas provenientes de diferentes teóricos da "virada prática", como Giddens, Bourdieu, Foucault e Schatzki, e, também referências a outras viradas como a "virada narrativa", "virada linguística" e a "virada comunicativa". Essas viradas representariam tanto chamadas de autores centrais do campo para temáticas ainda não desenvolvidas, quanto o próprio desenvolvimento de estudos diferenciados dentro do campo, relacionadas a pontos de inflexão na produção científica.

Em relação às chamadas feitas dentro do campo, destaca-se aquela realizada por Clegg, Carter e Kornberger (2004) que avaliam que o desenvolvimento da perspectiva da estratégia baseada na prática envolve seis categorias: (1) poder; (2) identidade profissional; (3) atores não humanos; (4) ética; (5) linguagem; e (6) instituições, algumas presentes no texto seminal de Whittington (1996), enquanto outras (linguagem e atores não humanos) representam novas possibilidades. Quanto às pesquisas do campo de SAP, Vaara e Whittington esclarecem que análises organizacionais baseadas em práticas tem se tornado mais comuns e que a expressão 'como prática' deste campo de estudos tem duplo sentido, como aproximação do mundo dos praticantes, assim como o compromisso com as teorias sociais da prática.

Os méritos dos estudos bibliométricos e sociométricos brasileiros de SAP (Walter \& Augusto, 2011; 2012, Walter, Bachl \& Barbosa, 2012, Okayama, Gag \& Oliveira Júnior, 2014, Maia, Di Serio \& Alves Filho, 2015) residem na tentativa de verificar ao longo dos anos estudos o crescimento do campo e os temas recorrentes, assim como os praticantes aos quais as pesquisas se referem, tanto nacionais quanto internacionais. Percebe-se que a SAP apresenta um vultoso crescimento, principalmente nos últimos quatro anos. Uma evidência encontrada nesses estudos referese ao foco na alta e média gerência em detrimento daqueles mais relacionados às práticas no cotidiano das organizações, apesar da constante chamada dos autores da SAP para a ampliação dos indivíduos envolvidos no strategizing. Merece destaque também a contribuição dos estudos brasileiros de SAP, por evidenciarem outros praticantes além daqueles inseridos em corporações multinacionais ou em organizações formais, algo relevante para o campo em âmbito internacional.

Notadas as contribuições dos estudos brasileiros, é necessário destacar a necessidade de maior aprofundamento, tanto teórico quanto epistemológico ao se analisar as influências que permeiam o campo e, conforme discutido por Vaara e Whittington (2012), no compromisso com as teorias sociológicas da prática, cujos autores são muitas vezes citados em passant, para legitimação dos textos e não para uma discussão profícua (Paiva et al., 2015).

Neste artigo visa-se compreender os autores e temas centrais da SAP a partir de uma combinação de procedimentos bibliométricos e sociométricos, em que são analisados 103 artigos com o auxílio do software CiteSpace (Chen, 2006) para a análise de redes, pontos de inflexão e research front; e NVivo, para a análise de conteúdo das categorias analíticas. Esses procedimentos são tomados como base considerando as referências centrais, textos do campo mais citados (9 artigos), e os pontos de inflexão (4 artigos). Este processo visa identificar também quais categorias adquirem maior importância no campo e quais são relegadas a um segundo plano. Dessa forma, perguntase, como desenvolveu-se o campo de Estratégia como Prática a partir de $\mathbf{1 9 9 6 ?}$

Diante do exposto, tem-se o objetivo de analisar a trajetória do campo da estratégia como prática no período de 1996 a 2015. Especificamente, almeja-se (a) apresentar um panorama geral da produção científica sobre estratégia como prática; (b) discutir e problematizar os research fronts e intelectual bases do campo; (c) verificar como se dão as suas "viradas", relacionando-as aos pontos de inflexão da produção científica; e (d) verificar categorias centrais e periféricas do campo. Finalmente, este artigo é composto por (1) esta introdução; (2) fundamentação teórica de revisões de literatura e estudos bibliométricos e sociométricos e (3) de SAP; (4) procedimentos metodológicos; (5) resultados alcançados, (6) discussão e (7) considerações finais.

\section{REVISÕES DE LITERATURA, ESTUDOS BIBLIOMÉTRICOS E SOCIOMÉTRICOS}

Neste breve tópico tem-se por objetivo apresentar conceitos e exemplos de revisões de literatura e estudos bibliométricos e sociométricos. Essa discussão é justificada pela polissemia e diversidade de conceitos dentro de revisões de literatura, que dificultam sua realização por pesquisadores não familiarizados com seus métodos, ainda mais aqueles que recentemente ingressaram na pesquisa científica. Mais do que buscar uma classificação rígida dos tipos de revisão, são apresentadas as principais possibilidades e exemplos de artigos que guardam características destes. Também são apresentados estudos sociométricos e bibliométricos, comumente utilizados no campo de SAP, principalmente por autores brasileiros. 
Cabe ressaltar que vários artigos apresentam diferenças dos métodos geralmente propostos para cada tipo de estudo (inclusive o presente artigo) o que não desvaloriza os estudos realizados, desde que estes apresentem rigor metodológico e coerência em sua elaboração, ou ainda refinamento teórico suficiente para revisões não sistemáticas. Defende-se ainda que técnicas e softwares bibliométricos e sociométricos podem contribuir para a escolha de artigos em uma revisão de literatura, permitindo a análise e refinamento de grande quantidade de material, o que facilita a realização desses estudos em campos que já apresentam vasta literatura.

\subsection{Revisões de Literatura}

Segundo Mancini e Sampaio (2006), as revisões de literatura se caracterizam pela realização de uma síntese das informações disponibilizadas em estudos relevantes e determinada área ou tema, existem diversos tipos, que seguem metodologias diferenciadas. As autoras ainda evidenciam que a revisão pode ser parte integrante de um estudo, como uma dissertação ou tese, ou ainda pode ser o artigo cientifico em si. Figueiredo (1990) traz que as revisões de literatura cumprem dois importantes papéis: integram o desenvolvimento da ciência, num papel histórico e fornecem a pesquisadores, estudantes e profissionais da área informações sobre o desenvolvimento de certo tema, servindo de meio de atualização.

As revisões podem classificadas em três tipos, de acordo com o método de elaboração utilizado: (i) revisão narrativa e (ii) revisão sistemática.

A revisão narrativa é aquela que não apresenta critérios explícitos e sistemáticos para sua elaboração (uma revisão não-sistemática), envolvendo fortemente a subjetividade e as escolhas teóricas do autor, pode ser relacionada ao referencial teórico de dissertações e teses. Na revisão sistemática, segundo Rumrill, Fitzgerald e Merchant (2010), objetiva-se remodelar informações existentes a priori de forma a contribuir para novas perspectivas, tanto para informar as práticas atuais dos profissionais e pesquisadores quanto para abrir novas possibilidades de pesquisa. A revisão feita por Clegg, Carter e Kornberger (2004), na qual discutem a virada para a prática nos estudos sobre estratégia, é um exemplo de revisão narrativa, na qual são elencadas categorias de análise importantes para a realização de novos estudos de SAP a partir do entendimento dos autores.

A revisão sistemática pode ser entendida a partir de sua oposição à revisão narrativa: cujo caráter discursivo e descritivo dificulta a reprodutibilidade, ou seja, impossibilita a realização de novas revisões com método semelhante. Mancini e Sampaio (2006) apresentam as revisões sistemáticas como aquelas que são desenhadas para serem metódicas, explícitas e passíveis de reprodução, evidenciando possibilidades de novas investigações e métodos de pesquisa. Para as autoras, uma revisão sistemática deve obrigatoriamente uma pergunta de pesquisa clara, uma estratégia de busca adequada, estabelecimento de critérios de inclusão e exclusão e uma análise criteriosa da literatura selecionada.

A revisão integrativa, de aspecto mais amplo, por possibilitar a análise conjunta de literatura teórica e empírica, também segue um protocolo pré-estabelecido e também pode ser considerada uma forma de revisão sistemática (Botelho et al., 2011).

No quadro 01 são apresentados artigos que guardam características de revisões sistemáticas, lembrando que neste próprio artigo, a partir de técnicas sociométricas e bibliométricas, é feita uma revisão sistemática de literatura a fim de aprofundar o conhecimento sobre o desenvolvimento do campo de SAP.

\begin{tabular}{|c|c|c|}
\hline ESTUDO & METODOLOGIA & CONTRIBUIÇÃO \\
\hline $\begin{array}{c}\text { Jarzabkowski } \\
\text { e Spee } \\
\text { (2009) }\end{array}$ & $\begin{array}{l}\text { - Artigos e capítulos de livro } \\
\text { publicados ou em publicação que } \\
\text { abordem explicitamente a Estratégia } \\
\text { como prática. } \\
\text { - Análise de conteúdo. }\end{array}$ & $\begin{array}{l}\text { - A agenda de pesquisa deve procurar estabelecer } \\
\text { uma relação maior entre aspectos micro e macro } \\
\text { nas análises e fundamentar os resultados de } \\
\text { desempenho nas pesquisas em SAP. }\end{array}$ \\
\hline $\begin{array}{l}\text { Vaara e } \\
\text { Whittington } \\
(2012)\end{array}$ & $\begin{array}{l}\text { - Revisão de artigos } \\
\text { publicados a partir de } 2003 \text { em } \\
\text { periódicos. } \\
\text { - } 57 \text { artigos analisados; } \\
\text { - Categorias: praxis, práticas e } \\
\text { praticantes. } \\
\end{array}$ & $\begin{array}{l}\text { - A pesquisa em estratégia como prática tem } \\
\text { ajudado na inserção de teorias sociológicas na } \\
\text { administração estratégica, além de oferecer } \\
\text { resultados alternativos à performance econômica } \\
\text { das organizações e promovido novas metodologias. }\end{array}$ \\
\hline $\begin{array}{l}\text { Rusko } \\
\text { (2013) }\end{array}$ & $\begin{array}{l}\text { - Revisão (10 artigos) com o objetivo } \\
\text { de discutir diferentes conceitos de } \\
\text { estratégia e "strategy work". } \\
\text { - Categorias: Estratégia por si própria } \\
\text { e Estratégias de gestão. }\end{array}$ & $\begin{array}{l}\text { - Existem duas perspectivas principais de estudos } \\
\text { de estratégia: uma mais descritiva, denominada a } \\
\text { "estratégia por si própria", e outra mais prescritiva, } \\
\text { as chamadas "estratégias de gestão". A estratégia } \\
\text { como prática se encaixa na primeira perspectiva; }\end{array}$ \\
\hline
\end{tabular}




\begin{tabular}{|c|c|c|}
\hline $\begin{array}{l}\text { Seidl e } \\
\text { Whittington } \\
\text { (2014) }\end{array}$ & $\begin{array}{l}\text { - Revisão de trabalhos de estratégia } \\
\text { como prática publicados na } \\
\text { Organization Studies; } \\
\text { - } 20 \text { Artigos teóricos e empíricos; }\end{array}$ & $\begin{array}{l}\text { - Os autores dividem os trabalhos em eixos: } \\
\text { Foucault; Giddens; Bourdieu; Archer; Narratology } \\
\text { e Wittgeinstein. } \\
\text { - A agenda de pesquisa deve se atentar para uma } \\
\text { necessidade de estudos com enfoque em aspectos } \\
\text { macro; }\end{array}$ \\
\hline $\begin{array}{l}\text { Paiva et al. } \\
\text { (2015) }\end{array}$ & $\begin{array}{l}\text { - Revisão de escopo de } 46 \text { trabalhos } \\
\text { publicados em periódicos nacionais e } \\
\text { estrangeiros que apresentavam traços } \\
\text { da virada linguística nos estudos de } \\
\text { SAP; } \\
\text { - Categorias: discurso, linguagem e } \\
\text { comunicação; } \\
\text { - Relação dos trabalhos com autores e } \\
\text { temáticas da virada linguística; }\end{array}$ & $\begin{array}{l}\text { - Destaca a existência de traços da virada } \\
\text { linguística em estudos do campo de estratégia } \\
\text { como prática, contudo ressalta que ainda há muito } \\
\text { que se explorar; } \\
\text { - Produção no campo tem crescido } \\
\text { consideravelmente nos últimos } 5 \text { anos; } \\
\text { - Necessidade de se estudar autores como Jürgen } \\
\text { Habermas, Karl-Otto Apel, Hans-Georg Gadamer, } \\
\text { entre outros. }\end{array}$ \\
\hline
\end{tabular}

Figura 1 - Revisões Sistemáticas em SAP. Fonte: Elaborado pelos autores.

Uma síntese revela que a maioria dos estudos apesar de buscar compreender o campo da estratégia como prática avalia um número reduzido de artigos, mesmo que este tenha aumentado nas últimas revisões. Observa-se também que: (i) as revisões demonstram que a SAP é um campo plural formada por diversas 'correntes', com influências de 'viradas' e autores da sociologia e filosofia; (ii) busca se fortalecer apresentando suas contribuições para o entendimento das estratégias nas organizações; (iii) delimita várias agendas de pesquisas teóricas e empíricas; e (iv) é um tema em construção as suas bases intelectuais e linhas de pesquisas centrais.

\subsection{Estudos Bibliométricos e Sociométricos}

As duas técnicas centrais do estudo, são sucintamente apresentadas para facilitar o entendimento sobre a metodologia de pesquisa: a (1) bibliometria é uma técnica quantitativa utilizada para entender como o conhecimento científico é produzido e difundido (Araújo, 2006); enquanto a (2) sociometria é uma técnica de investigação das relações existentes em um campo de estudos (Moreno, 1972).

Em estudos bibliométricos pode-se utilizar análises de citações e co-citações, por meio de métodos estatísticos e matemáticos, são especialmente úteis, juntamente à análise de redes, para tratar grandes volumes de informação, em que uma análise de conteúdo usual não seria viável, conforme destacam Pinto, Serra e Ferreira (2014).

Bibliometric studies aim to detect intellectual networks [...], to assess trends on a given subject or discipline, to identify main theories and more productive scholars or institutions or to identify and map the intellectual structure of a discipline or area of study (Pinto et al. 2014, p. 345).

No presente estudo, a bibliometria serve como base para a realização de uma revisão de literatura sistemática, facilitando a escolha dos artigos mais relevantes do campo, auxiliada pelo uso de turning points e research fronts, do software sociométrico CiteSpace.

É importante ressaltar que no campo de estudos da Estratégia como Prática, outros trabalhos de revisão de literatura, sendo alguns deles de caráter bibliométrico e sociométrico, foram realizados, entretanto, conforme Gag, Okayama e Oliveira (2014) e Paiva et al. (2015), ainda é possível explorar o campo a partir da análise da produção bibliográfica que o constitui ou influencia.

Assim, na Figura 2, abaixo, é apresentada uma breve síntese de outras revisões realizadas no âmbito da estratégia como prática, destacando seus procedimentos metodológicos e contribuições. 


\begin{tabular}{|c|c|c|}
\hline EST & METODOLOGIA & CONTRIBUIÇÃO \\
\hline $\begin{array}{c}\text { Walter e } \\
\text { Augusto } \\
\text { (2011) }\end{array}$ & $\begin{array}{l}\text { - Sociometria (nacional e } \\
\text { internacional). } \\
\text { - Diversas bases de dados } \\
\text { internacionais, Sciello Brasil e Anais } \\
\text { da ANPAD. } \\
\text { - Construção de redes - } 24 \text { estudos } \\
\text { publicados no Brasil e } 76 \text { no exterior }\end{array}$ & $\begin{array}{l}\text { - Analisa-se o nível de institucionalização da } \\
\text { Estratégia como Prática. } \\
\text { - Defasagem entre as primeiras publicações na } \\
\text { literatura internacional e na brasileira. } \\
\text { - Crescimento do campo no Brasil. }\end{array}$ \\
\hline $\begin{array}{c}\text { Walter e } \\
\text { Augusto } \\
\text { (2012) }\end{array}$ & $\begin{array}{l}\text { - Buscas em bases de dados, sites, } \\
\text { anais de eventos e periódicos. } \\
\text { - } 77 \text { artigos empíricos (Brasil e } \\
\text { exterior). } \\
\text { - Análise de conteúdo - categorias: } \\
\text { práticas estratégicas; prática } \\
\text { estratégica e strategizing; e } \\
\text { strategizing. }\end{array}$ & $\begin{array}{l}\text { - Analisa o delineamento metodológico dos } \\
\text { estudos. } \\
\text { - Pesquisas focam o nível do "topo. } \\
\text { - O tema principal de pesquisa é Strategizing. } \\
\text { - O delineamento principal é o estudo de caso e } \\
\text { coletando dados por meio de entrevistas, } \\
\text { observação e documentos. }\end{array}$ \\
\hline $\begin{array}{c}\text { Walter, } \\
\text { Bachl e } \\
\text { Barbosa } \\
(2012)\end{array}$ & $\begin{array}{l}\text { - Pesquisa bibliométrica } \text { e } \\
\text { sociométrica de } 143 \text { artigos do } \\
\text { exterior e } 64 \text { brasileiros; } \\
\text { - Relações entre redes de autores e } \\
\text { instituições; }\end{array}$ & $\begin{array}{l}\text { - A rede de autores estrangeiros é pouco } \\
\text { fragmentada e concentra-se em poucos autores. No } \\
\text { caso brasileiro, observa-se ainda uma rede muito } \\
\text { fragmentada, com pouca cooperação, e sem autores } \\
\text { e instituições preponderantes; }\end{array}$ \\
\hline $\begin{array}{c}\text { Maciel e } \\
\text { Augusto } \\
(2013)\end{array}$ & $\begin{array}{l}\text { - Revisão de } 59 \text { artigos publicados em } \\
\text { periódicos com alto fator de impacto } \\
\text { para entender o movimento da } \\
\text { practice turn nos estudos de } \\
\text { estratégia; }\end{array}$ & $\begin{array}{l}\text { - A virada prática está concentrada em trabalhos } \\
\text { orientados ao vocabulário da sociologia da } \\
\text { regulação; } \\
\text { - A finalização da virada não está completa. } \\
\text { - É preciso recuperar a organização no estudo da } \\
\text { prática, redefinindo o próprio termo "organização"; }\end{array}$ \\
\hline $\begin{array}{c}\text { Okayama, } \\
\text { Gag e } \\
\text { Oliveira } \\
\text { Junior (2014) }\end{array}$ & $\begin{array}{l}\text {-Revisão sistemática bibliométrica de } \\
84 \text { trabalhos divididos entre } \\
\text { estrangeiros e nacionais; } \\
\text { - Categorias: Temática dos estudos; } \\
\text { nível organizacional; re base } \\
\text { epistemológica e ontológica de cada } \\
\text { abordagem; }\end{array}$ & $\begin{array}{l}\text { - Os autores questionam se o ingresso tardio do } \\
\text { Brasil no campo é fruto da inexistência de uma } \\
\text { teoria organizacional genuinamente brasileira; } \\
\text { - Há um maior número de análises no topo das } \\
\text { organizações em detrimento de outros níveis; tal } \\
\text { cenário contradiz uma das principais agendas de } \\
\text { pesquisa do campo que propõe o estudo de todos } \\
\text { os níveis; }\end{array}$ \\
\hline $\begin{array}{l}\text { Maia, Serio e } \\
\text { Alves Filho } \\
\quad(2015)\end{array}$ & $\begin{array}{l}\text { - Buscas na Web of Science (72 } \\
\text { artigos) e Google Scholar (2372 } \\
\text { dados); } \\
\text { - Análise bibliométrica e } \\
\text { sociométrica; } \\
\text { - Construção de redes. }\end{array}$ & $\begin{array}{l}\text { - Destaca a proeminência do Reino Unido na } \\
\text { produção acadêmica e nas redes de autores } \\
\text { presentes no campo; } \\
\text { - Evidenciam uma maior concentração de artigos } \\
\text { publicados em periódicos das áreas de Estudos } \\
\text { Organizacionais e Gestão; }\end{array}$ \\
\hline
\end{tabular}

Figura 2 - Síntese das revisões de literatura sobre estratégia como prática.

Fonte: Elaborado pelos autores.

Os estudos acima foram realizados por autores brasileiros e destacam conjuntamente o desenvolvimento do campo da SAP no Brasil que apesar de ainda incipiente se comparado a vertente inglesa está em crescimento acelerado. Estes estudos visaram além de apresentar relações bibliométricas e sociométricos destacar as categorias centrais, as bases epistemológicas e ontológicas, os métodos de pesquisa, os procedimentos de coleta de dados, dentre outras questões.

\section{FUNDAMENTOS TEÓRICOS ESTRATÉGIA COMO PRÁTICA}

O desenvolvimento do campo de estudos em estratégia foi, historicamente, marcado por abordagens prescritivas, de forte orientação microeconômica e direcionada para a alta gerência (Whittington, 2006, Harwood, 2011). Conforme Canhada e Rese (2009), embora algumas correntes se atentassem em investigar fenômenos micro organizacionais, tais como a Visão 
Baseada em Recursos ou a Abordagem Processual, era perceptível a ausência de estudos preocupados em discutir aspectos voltados à agência humana, englobando outros tipos de atores e níveis organizacionais, bem como sua relação com as estruturas sociais. Foi em meio a esse cenário, a partir de contribuições dos estudos organizacionais e da teoria social que emergiu a abordagem da estratégia como prática (Golsorkhi, Rouleau, Seidl \& Vaara, 2010).

A perspectiva da SAP caracteriza-se, principalmente, pela proposição de que a estratégia não é mais algo que as organizações possuem, mas, sim, aquilo que as pessoas fazem (Jarzabkowski et al., 2007; Johnson, Langley, Melin \& Whittington, 2007). Para Walter et al. (2012, p. 309), “[...] essa abordagem procura descobrir como as pessoas realizam seu trabalho dentro da organização", de modo que o pesquisador está interessado no 'trabalho estratégico' (strategizing), procurando identificar: quem faz, o que eles fazem e quais as implicações de suas ações na formação da estratégia organizacional (Jarzabkowski, \& Spee, 2009). Para Jarzabkowski e Balogun (2009), o strategizing se baseia nas práticas organizacionais que afetam o processo e a geração de resultados a partir de estratégias.

Essa abordagem, conforme Jarzabkowski et al. (2007), dá maior ênfase na relação entre aspectos micro e macro das estratégias corporativas, permeados por práticas sociais. Esses autores entendem as estratégias como atividades que estão conectadas com práticas específicas do universo organizacional, tais como o planejamento estratégico, relatórios anuais, reuniões, conferências, etc.

Conforme Jonhson et al. (2007), a estratégia como prática trouxe importantes avanços para os estudos de estratégia ao procurar compreender que são as pessoas que realmente constroem e reproduzem estratégias, além de fomentar a abertura do campo de trabalhos para outras disciplinas e áreas do conhecimento, oferecendo uma agenda de pesquisa instigante. Nessa direção, Vaara e Whittington (2012) argumentam que a abordagem também está interessada em discutir e ampliar o conceito de performance organizacional, desvinculando-o da noção de desempenho econômico, eficiência, indicadores de produção, etc. Além disso, a pesquisa em estratégia como prática procura abranger outros tipos de organizações, envolvendo empresas sem fins lucrativos e organizações públicas, bem como oferece maior abertura para métodos de pesquisa qualitativos e em profundidade.

Uma característica fundamental para $\mathrm{O}$ desenvolvimento do campo consiste na influência de diferentes pensadores e 'viradas' existentes na teoria social contemporânea, tais como: a 'virada prática' (principalmente), 'virada narrativa', 'virada comunicativa', 'virada linguística', etc. recorrendo a estudiosos como Giddens, Bourdieu, Foucault, Latour, Schatzki, Wittgenstein, entre outros para a construção de frameworks de análise do fenômeno da estratégia nas organizações (Whittington, 2006; Walter \& Augusto, 2011). Okayama et al. (2014) destacam como outras influências a teoria da estruturação, teoria institucional, visão baseada na prática, teoria da atividade, análise de discurso crítica, teoria das representações sociais e teoria ator-rede.

Conforme revisão de Jarzabkowski e Spee (2009), até o ano de publicação de seu trabalho, o campo estava em amplo crescimento, com um grande número de publicações, congressos específicos, comunidades virtuais e livros que estabeleciam conceitos em comum, agendas de pesquisa, métodos e estudos empíricos. Destaca-se que o procedimento mais usual de pesquisa é a proposta metodológica de Whittington (2006) que entende a estratégia como um fenômeno constituído por três categorias que se relacionam: práxis, práticas e praticantes (Brito, Brito, Borges \& Andrade, 2014; Jarzabkowski et al., 2007; Jarzabkowski \& Spee, 2009). Jarzabkowski et al. (2007) afirmam que este modelo com práxis, práticas e praticantes é o arcabouço conceitual para o estudo da estratégia como prática, onde o strategizing ocorre no nexo entre as três categorias.

De forma geral, sabe-se que: a SAP se desenvolve com uma tendência de crescimento no número de publicações; busca por relacionar aspectos micro e macro nas análises e englobar diferentes atores da organização; é marcada pela inserção de teorias sociológicas; desenvolve novas abordagens teóricas e metodológicas a partir de categorias como materialidade, discurso, comunicação, poder e narrativa; as pesquisas realizadas possuem como delineamento principal o estudo de caso por meio de entrevistas, observação e documentos; e busca consolidação como abordagem voltada para uma forma de pensar a estratégia como prática (Whittington, 2006; Jarzabkowski et al., 2007; Jarzabkowski \& Spee, 2009; Harwood, 2011; Brito et al., 2014). No tópico seguinte, é feita uma apresentação de aspectos básicos de revisão de literatura e estudos bibliométricos e sociométricos, com o intuito de familiarizar outros autores sobre essa possibilidade de investigação, assim como possibilitar a replicação desse estudo, para o campo de SAP ou outros.

\section{PROCEDIMENTOS METODOLÓGICOS}

A opção de trabalhar com dados secundários, a partir de trabalhos publicados e indexados na base Web of Science, possibilita uma visão ampliada do campo da SAP, de modo a ser possível entender a configuração e tendências da produção científica. Cabe esclarecer que esta é uma pesquisa descritiva, na qual foi feito um estudo bibliométrico e sociométrico.

A partir do uso de tais técnicas, realizou-se uma pesquisa onde foram analisadas (1) as referências centrais do campo; (2) os textos mais citados; e (3) os pontos de inflexão; e (4) as categorias centrais e 
Desvelando o Campo da Estratégia como Prática e suas Relações

periféricas. Um resumo das etapas do estudo é apresentado na Figura 1, as quais são discutidas em seguida.

\begin{tabular}{|c|l|}
\hline ETAPA & \multicolumn{1}{c|}{ DESCRIÇão } \\
\hline $\begin{array}{c}\text { Identificação do tema e questão } \\
\text { de pesquisa }\end{array}$ & $\begin{array}{l}\text { (a) Campo de Estratégia como Prática e (b) como, a partir de 1996, } \\
\text { desenvolveu-se o campo de estratégia como prática? }\end{array}$ \\
\hline $\begin{array}{c}\text { Busca dos artigos e critérios de } \\
\text { seleção }\end{array}$ & $\begin{array}{l}\text { (a) Uso da ISI Web of Science; (b) busca por "strategy as practice"; (c) } \\
\text { com recorte temporal de 1996 a julho de 2015 (d); escolha por "article”. }\end{array}$ \\
\hline $\begin{array}{c}\text { Sistematização e apuração da } \\
\text { base de dados criada }\end{array}$ & $\begin{array}{l}\text { (a) utilização de Analyze Results e Create Citation Report para elaboração } \\
\text { de quadros; (b) pesquisa salva como plain text para uso no software } \\
\text { CiteSpace e exportada para o Endnote X5; (c) busca pelos arquivos em } \\
\text {-pdf no Endnote X5, para quantificação no NVivo e leitura (textos para } \\
\text { discussão) }\end{array}$ \\
\hline $\begin{array}{c}\text { Criação de sociogramas e } \\
\text { análise dos turning points }\end{array}$ & $\begin{array}{l}\text { (a) Criação de redes de referências, coautoria, países e autores, palavras- } \\
\text { chave e áreas do conhecimento; (b) Verificação dos turning points nas } \\
\text { redes de autoria e de referências. }\end{array}$ \\
\hline Análise de conteúdo dos artigos & Pesquisa por autores, categorias e presença de viradas nos artigos. \\
\hline Leitura dos textos selecionados & $\begin{array}{l}\text { Leitura, fichamento e categorização dos artigos mais citados, textos mais } \\
\text { referenciados e turning points. }\end{array}$ \\
\hline
\end{tabular}

Figura 3 - Procedimentos metodológicos

Fonte: Elaborado pelos autores.

O ano inicial da busca, 1996, foi escolhido por ser o ano de publicação do texto Whittington (1996), Strategy as Practice, que apresenta a perspectiva de pesquisas da estratégia voltadas para as práticas, $\mathrm{o}$ ano final foi 2015, cabendo destacar que a busca foi realizada em junho de 2015. Comumente os estudos bibliométricos e sociométricos não utilizam o ano atual das publicações, ou em andamento, por ainda não se ter a dimensão total das publicações, nesse caso foi considerada a produção de 2015 devido ao grande volume de produção desse ano, que pode trazer relações, que, caso 2015 fosse desconsiderado, não seriam reveladas.

A busca na ISI Web of Science considerou apenas a 'Coleção Principal do Web of Science', por ser a única com todas as informações necessárias para se utilizar o software sociométrico Citespace, dessa forma, as bases Biological Abstracts, Derwent Innovations Index, $\mathrm{KCI}$ - Base de Dados de Periódicos Coreanos e Scielo Citation Index não foram consideradas nesse estudo.

Pesquisou-se "strategy as practice" e (strategyas-practice" (termos equivalentes) em tópicos, ou seja, considerou-se título, resumo, palavras-chave do autor e keyword plus (sistema padronizado de palavras-chave da ISI Web of Science) dos textos da base. Como resultado foi encontrado um total de 128 textos (a busca em todas as bases de dados forneceu 142 textos), entre eles artigos, revisões de livro e editoriais, aplicando o filtro de 'tipos de documento' 'article', chegou-se a 103 artigos.

Os 103 artigos tiveram todas as informações disponíveis salvas em plain text, formato no qual é possível utilizar o Citespace. As referências também foram salvas no Endnote X5, para então ser feita a busca pelos pdfs dos artigos, foram encontrados 100 pdfs, dessa forma, mesmo que os dados gerais tratem de 103 artigos (panorama geral e redes), a análise de conteúdo e a presença das categorias analíticas foi verificada em apenas 100 artigos.

Nos resultados foram construídos gráficos e tabelas destacando a produção e citações ano a ano, artigos mais citados, autores mais prolíficos, palavras chave-mais citadas, assim como as ocorrências dos principais autores da virada prática.

Além disso, foi analisado a presença das categorias poder, instituições, materialidade, identidade, ética, linguagem, atores não humanos, práxis, praticantes e prática indicadas por Clegg et al. (2004) e Whittington (2006), estas categorias são justificadas pela importância desses autores para a SAP e para os estudos de estratégia como um todo, também são em sua maioria temas recorrentes das pesquisas de SAP, ou temas que adquiriram relevância nos últimos anos. Posteriormente, foi analisado a presença dessas categorias nos textos da base intelectual e pontos de inflexão.

A discussão do artigo gira em torno dos textos considerados research front ou pontos de inflexão, a seguir são apresentados esses dois conceitos essenciais para o estudo, juntamente com o conceito de base intelctual, que os complementa. Chen (2006, p. 359) evidencia que um research front, conceito cunhado por Price, "characterize the transient nature of a research field. Price observed what he called the immediacy factor: There seems to be a tendency for scientists to 
Desvelando o Campo da Estratégia como Prática e suas Relações

cite the most recently published articles. In a given field, a research front refers to the body of articles that scientists actively cite". Denota-se ainda que um research front é o estado da arte de um campo de pesquisa.

Se o research front representa o estado da arte de determinado campo científico, o que é citado por esse research front forma a base intelectual. Persson, citado por Chen (2006, p. 361), traz uma distinção mais clara: "[...] in bibliometric terms, the citing articles form a research front, and the cited articles constitute an intellectual base". No software Citespace, a base intelectual é formada a partir da rede de co-citações.

Também é importante verificar os pontos de inflexão, chamados de pivotal points ou tipping points. De acordo com Chen (2006, p. 360): "we [...] need to identify the focus of a research front at a particular time in the context of its intellectual base, to reveal significant intellectual turning points as a research front evolves, and to discover the interconnections between different research fronts".

Chen (2006) ainda argumenta que a relevância de um ponto de inflexão pode ser verificada através da análise dos próprios textos (trechos, citações, argumentos, categorias etc,), comparando-os aos pressupostos centrais do campo e utilizando ferramentas de busca e operacionalização de textos.

A discussão dos textos considerados research front ou pontos de inflexão permitem aprofundar o conhecimento sobre o campo de SAP, não remetendo apenas aos artigos mais citados (na base como um todo ou na rede e co-citações), mas também àqueles que representam pontos de mudança relevantes na produção científica em SAP.

\section{RESULTADOS}

Os resultados obtidos foram divididos em duas subseções: (1) panorama geral, em que é apresentada a caracterização da produção científica em Estratégia como Prática, com tabelas e redes; e (2) research front e pontos de inflexão do campo de SAP, em que são apresentados os textos a serem discutidos posteriormente.

\subsection{Panorama Geral}

O artigo de Richard Whittington (1996), Strategy as Practice, é o trabalho seminal do campo, de modo que a partir dessa publicação, várias outras desenvolveram a temática, principalmente a partir de 2007. Na Figura 3 é possível observar a evolução no número de produções do campo, destacando a lacuna existente entre Whittington (1996) e o segundo artigo publicado, Jarzabkowski e Wilson (2002) e Jarzabkowski (2003). Em 2004, as publicações de Chia (2004), Clegg, Carter \& Kornberger (2004) e Mckiernan e Carter (2004) indicam ligeiro crescimento do campo (Robert Chia e Stewart Clegg também estão entre os autores mais citados), contudo, é a partir de 2007 (11 artigos) que se observa um salto no número de publicações, com 19 trabalhos publicados.

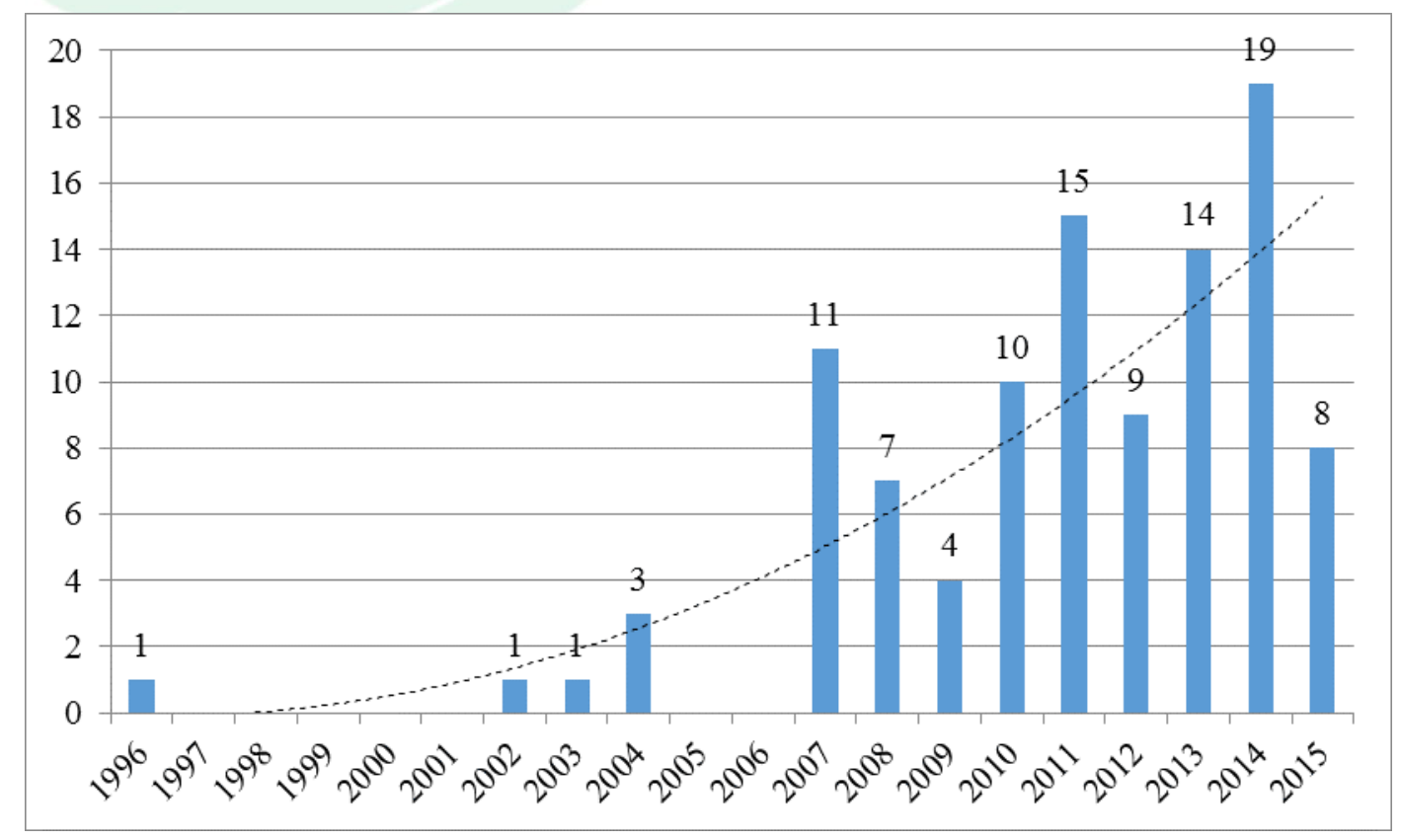

Figura 4 - Número de Artigos por Ano Fonte: Elaborado pelos autores. 
Considerando a quantidade de citações, os últimos seis anos apresentam um aumento considerável, evidenciando o crescimento do campo, conforme mostra a Figura 4. Novamente, o ano de 2007 aparece como ponto importante para o campo, apresentando aumento de $320 \%$ com relação ao ano anterior. Apesar de ser considerado apenas o primeiro semestre de 2015, este já apresenta quantidade maior de citações que todos os outros anos, exceto 2013 e
2014, mostrando uma maior consolidação no número de citações de trabalhos anteriores publicados no campo.

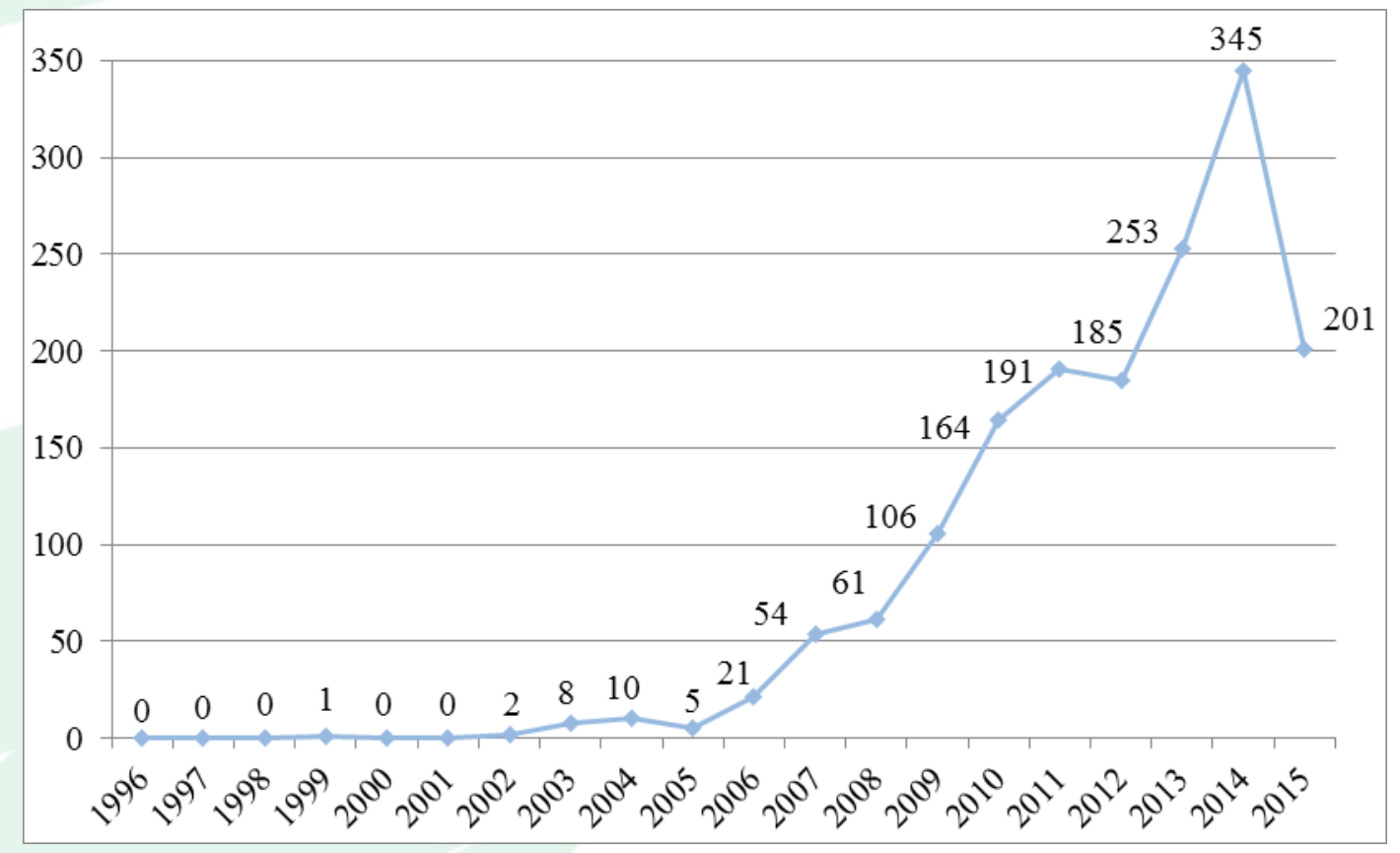

Figura 5 - Citações por ano

Fonte: Elaborado pelos autores.

Os dez textos mais citados (Cit.) são apresentados na Tabela 1 (citações indexadas à Web of Science). Nota-se a relevância de Jarzabkowski, com quatro artigos, entre eles o $1^{\circ}, 3^{\circ}$ e $4^{\circ}$ mais citado e de
Whittington, com três artigos, sendo que o artigo seminal do campo (Whittington, 1996) é o segundo mais citado.

Tabela 1 - Artigos mais citados

\begin{tabular}{|c|c|c|c|}
\hline $\operatorname{AUTOR}(\mathbf{E S})$ & ARTIGO & ANO & CIT. \\
\hline $\begin{array}{l}\text { Jarzabkowski, Balogun \& } \\
\text { Seidl }\end{array}$ & Strategizing: The challenges of a practice perspective & 2007 & 164 \\
\hline Whittington & Strategy as practice & 1996 & 146 \\
\hline Jarzabkowski & $\begin{array}{l}\text { Strategic practices: an activity theory perspective on } \\
\text { continuity and change }\end{array}$ & 2003 & 101 \\
\hline Jarzabkowski \& Spee & $\begin{array}{l}\text { Strategy-as-practice: A review and future directions for the } \\
\text { field }\end{array}$ & 2009 & 95 \\
\hline Chia \& MacKay & $\begin{array}{l}\text { Post-processual challenges for the emerging strategy-as- } \\
\text { practice perspective: Discovering strategy in the logic of } \\
\text { practice }\end{array}$ & 2007 & 86 \\
\hline Mantere \& Vaara & $\begin{array}{l}\text { On the problem of participation in strategy: A critical } \\
\text { discursive perspective }\end{array}$ & 2008 & 63 \\
\hline
\end{tabular}


Desvelando o Campo da Estratégia como Prática e suas Relações

\begin{tabular}{|c|l|c|c|}
\hline Whittington & $\begin{array}{l}\text { Strategy practice and strategy process: Family differences } \\
\text { and the sociological eye }\end{array}$ & 2007 & 53 \\
\hline Seidl & $\begin{array}{l}\text { General strategy concepts and the ecology of strategy } \\
\text { discourses: A systemic-discursive perspective }\end{array}$ & 2007 & 53 \\
\hline Vaara \& Whittington & Strategy-as-practice: Taking social practices seriously & 2012 & 49 \\
\hline Jarzabkowski \& Seidl & The role of meetings in the social practice of strategy & 2008 & 48 \\
\hline
\end{tabular}

Fonte: Elaborado pelos autores.

Analisando os autores mais prolíficos, verificase novamente a importância dos trabalhos de Paula Jarzabkowski e Richard Whittington, com 13 e 8 artigos, respectivamente, seguidos por Seidl (6), Kaplan (4) e Paroutis (4). Ressalta-se que os artigos dos 10 autores mais prolíficos representam quase $50 \%$ do total (Tabela 2) e que a maioria dos autores do campo (145) possui apenas um artigo publicado e outros 11 autores possuem dois artigos publicados.

Tabela 2 - Autores mais prolíficos

\begin{tabular}{|l|c|c|}
\hline \multicolumn{1}{|c|}{ AUTOR } & ARTIGOS & \% DE 103 \\
\hline Jarzabkowski P. & 13 & $12,62 \%$ \\
\hline Whittington R. & 8 & $7,77 \%$ \\
\hline Seidl D. & 6 & $5,83 \%$ \\
\hline Kaplan S. & 4 & $3,88 \%$ \\
\hline Paroutis S. & 4 & $3,88 \%$ \\
\hline Chia R. & 3 & $2,91 \%$ \\
\hline Clegg S. & 3 & $2,91 \%$ \\
\hline Langley A. & 3 & $2,91 \%$ \\
\hline Mantere S. & 3 & $2,91 \%$ \\
\hline Vaara E. & 3 & $2,91 \%$ \\
\hline Total & $\mathbf{5 0}$ & $\mathbf{4 8 , 5 4 \%}$ \\
\hline
\end{tabular}

Fonte: Elaborado pelos autores.

Quanto à rede de autores, destaca-se a relação formada por Whittington, Jarzabkowski, Seidl, Kaplan, Vaara e Mantere como central. Jarzabkowski é a autora com maior número de ligações: Sarah Kaplan, David Seidl, Andreas Paul Spee, Michael Smets, Laure Cabantous, Julia Balogun e Richard Whittington. Este último também está ligado a Eero Vaara, um dos autores mais prolíficos do campo.

Considerando os países de origem das publicações, a Inglaterra é o país com maior número de artigos (43), seguido pelo Canadá (15), Austrália (10) e Estados Unidos (9). Evidencia-se também que os artigos de SAP estão presentes principalmente em periódicos voltados para Estudos Organizacionais e Administração em geral: Organization Studies (com 14 artigos publicados), e Human Relations (9), em detrimento dos periódicos focados em Estratégia, como Strategic Management Journal (3) e Strategic Organization (3).

Tão importante quanto analisar os artigos mais citados, assim como as relações entre países e instituições, é verificar as principais referências para o campo de estudos. O texto mais referenciado dentre os 103 artigos é Whittington (2006), com 66 citações, seguido por Johnson, Melin e Whittington (2003) - 47, Jarzabkowski et al. (2007) - 46, Jarzabkowski (2004) 43, Jarzabkowski (2005) - 38, Jarzabkowski e Balogun (2009) - 34, Samra-Fredericks (2003) - 34, Whittington (1996) - 31 e Balogun e Johnson (2004) 30. Os textos referenciados que aparecem como pontos de inflexão são Mintzberg (1973), Bourdieu (1990), Gioia e Chittipeddi (1991), Knights e Morgan (1991), Barry e Elms (1997) e Whittington (2003). Cabe destacar que entre os autores da "virada prática", apenas Pierre Bourdieu possui um texto considerado ponto de inflexão e nenhum deles está entre os textos mais citados, representados por textos do próprio campo. Conforme destacado por Chen (2006), há uma tendência de citar os textos mais atuais de autores mais influentes, dando forma à base intelectual de determinado campo, o que é confirmado no presente estudo, levando em conta a quantidade de citações dos textos de Whittington e, principalmente, de Jarzabkowski.

Notada a ausência de mais autores da virada prática e de outros clássicos, foi realizada a busca integral por meio do software NVivo 10, cujo resultado é apresentado na Tabela 3. Percebe-se que apesar da 
presença significativa de alguns autores, como Giddens, Bourdieu e Schatzki, o número de ocorrências é baixo, o que evidencia que muitas vezes esses autores são citados en passant, com o propósito de legitimação ou citação de determinada categoria que não é discutida no artigo. Autores relevantes para a virada prática, como De Certeau e Goffman, são pouco citados e o número de ocorrências é ainda menor que para os demais autores pesquisados, evidenciando que a obra destes foi pouco explorada no campo.]

Tabela 3 - Autores da Virada Prática no campo de SAP

\begin{tabular}{|l|c|c|c|c|}
\hline \multicolumn{1}{|c|}{ AUTOR } & QUANT. ARTIGOS & \% DE 103 & $\begin{array}{c}\text { CONTAGEM } \\
\text { TOTAL }\end{array}$ & MÉDIA/ARTIGO \\
\hline Giddens & 38 & $36,89 \%$ & 211 & 5,55 \\
\hline Bourdieu & 35 & $33,98 \%$ & 445 & 12,71 \\
\hline Schatzki & 34 & $33,01 \%$ & 204 & 6,00 \\
\hline Foucault & 25 & $24,27 \%$ & 149 & 5,96 \\
\hline Goffman & 13 & $12,62 \%$ & 64 & 4,92 \\
\hline De Certeau & 9 & $8,74 \%$ & 20 & 2,22 \\
\hline
\end{tabular}

Fonte: Elaborado pelos autores.

É interessante também pesquisar sobre as categorias centrais do campo. Primeiramente, a rede de palavras-chave criada no software CiteSpace é apresentada na Figura 5. Dentre as categorias de análise elencadas por Clegg et al (2004), poder (com 14 ocorrências) e identidade (8 ocorrências) aparecem como pontos de inflexão. As palavras-chave mais utilizadas, excluindo aquelas diretamente relacionadas ao campo de SAP, são sensemaking (25), desafios (25), organizações (23), administração (23), discurso (22), tomada de decisão (16) e conhecimento (15).

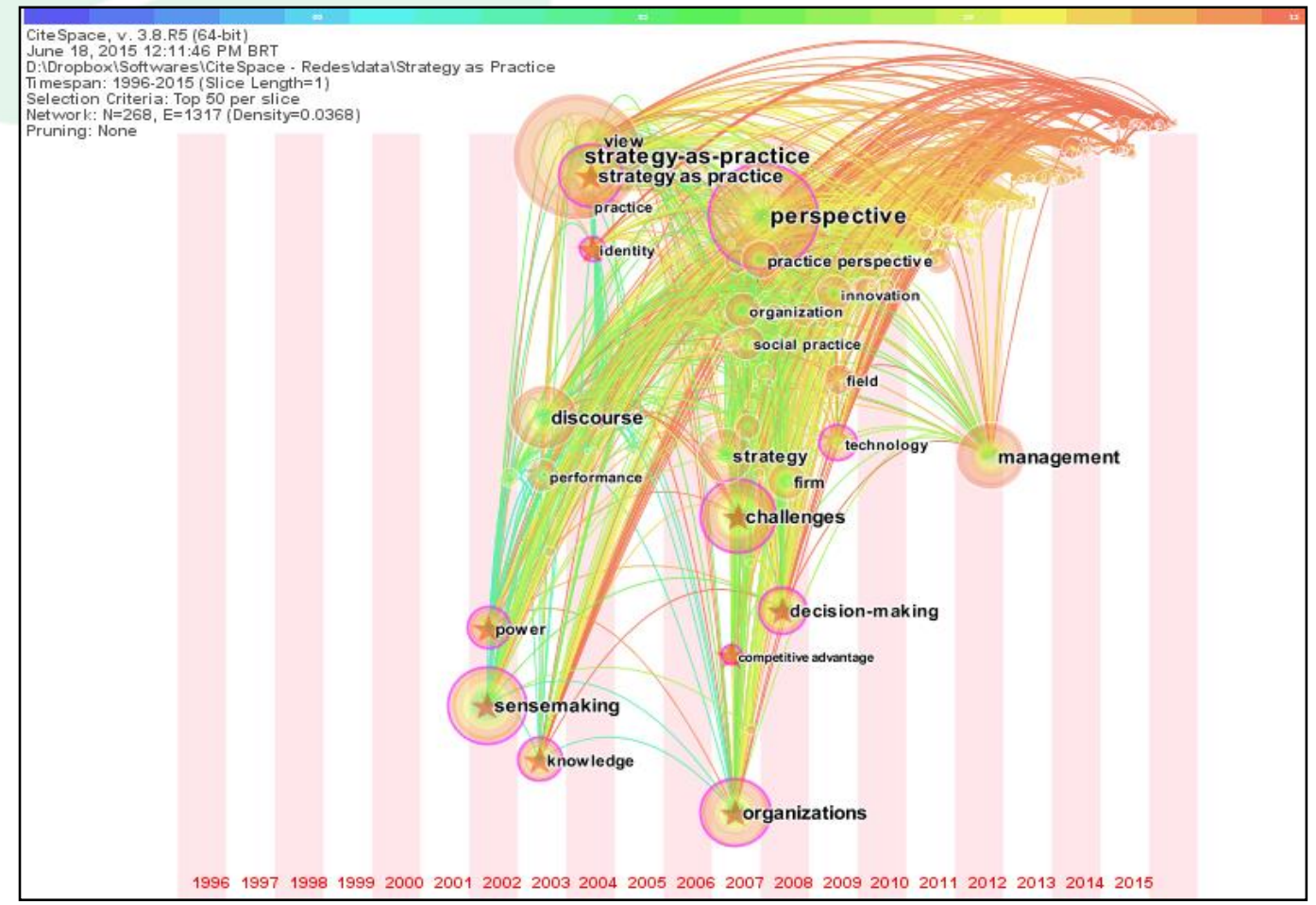

Figura 5 - Rede de palavras-chave Fonte: Elaborado pelos autores. 
Desvelando o Campo da Estratégia como Prática e suas Relações

Quando analisadas no software Nvivo 10, as categorias elencadas por Clegg et al. (2004) e Whittington (2006) estão presentes em boa parte da produção científica da área, com exceção de 'atores não humanos', com baixa representatividade, ainda que a categoria complementar 'materialidade' esteja presente em número considerável de artigos, conforme apresentado na Tabela 4. Considerando a contagem total de ocorrências das categorias, considera-se que poder e instituições são as categorias mais exploradas no campo. 'Materialidade', apesar de presente um número expressivo de artigos, apresenta baixa contagem de ocorrências, ocorrendo praticamente o mesmo com 'linguagem' e 'identidade'. As categorias 'ética' e 'atores não-humanos' são as menos exploradas na base de artigos selecionada, enquanto que 'práxis', mesmo presente em $50 \%$ dos artigos, é a categorias com maior média de ocorrências por artigo.

Tabela 4 - Presença das categorias de análise na produção científica em SAP

\begin{tabular}{|c|c|c|c|c|}
\hline CATEGORIAS & $\begin{array}{c}\text { QUANT. } \\
\text { ARTIGOS* }\end{array}$ & $\%$ DE 100 & $\begin{array}{c}\text { CONTAGEM } \\
\text { TOTAL* }\end{array}$ & MÉDIA/ARTIGO \\
\hline Poder & 91 & $91 \%$ & 1239 & 13,62 \\
\hline Instituições & 92 & $92 \%$ & 1509 & 16,40 \\
\hline Materialidade & 81 & $81 \%$ & 712 & 8,79 \\
\hline Ética & 27 & $27 \%$ & 304 & 11,26 \\
\hline Identidade & 80 & $80 \%$ & 583 & 7,29 \\
\hline Linguagem & 73 & $73 \%$ & 573 & 7,85 \\
\hline Atores não humanos & 11 & $11 \%$ & 19 & 1,73 \\
\hline Práxis & 50 & $50 \%$ & 592 & 11,84 \\
\hline Praticantes & 82 & $81 \%$ & 976 & 11,90 \\
\hline Prática** & 99 & $99 \%$ & 5381 & 54,35 \\
\hline \multicolumn{5}{|c|}{$\begin{array}{l}\text { *Na busca por palavras o critério da polaridade exatidão/similaridade, de } 1 \text { a } 5 \text {, (1 somente correspondência exata, até } 5 \\
\text { - incluindo generalizações) foi o valor } 2 \text { - incluindo palavras derivadas, para considerar tanto palavras no singular } \\
\text { quanto no plural e também adjetivações. } \\
\text { ** Excluídas as ocorrências de "strategy-as-practice" e "strategy as practice". }\end{array}$} \\
\hline
\end{tabular}

Fonte: Elaborado pelos autores.

Por fim, é apresentado um sociograma das áreas da ciência (segundo a classificação da base de dados Web of Science), indicando as relações entre elas, conforme a Figura 6 mostra. Percebe-se que grande parte dos artigos encontram-se em áreas tradicionalmente relacionadas à administração, como 'Negócios e Economia' (95 artigos), 'Administração' (89) e 'Negócios' (34). Ainda se destacam, mesmo que com quantidade muito inferior de artigos, 'Ciências
Sociais - outros tópicos' (14) e 'Ciências Sociais' (10). Há ainda uma variedade muito grande de áreas do saber, principalmente nos quatro últimos anos, indicando que o campo se desenvolve para outras áreas, mas de forma ainda vestigial. Entre as áreas encontram-se 'Ciência da Computação' (6), 'Administração Pública' (5), 'Planejamento e Desenvolvimento' (3), 'Ética' (1), 'Geografia' (1), dentre outras. 


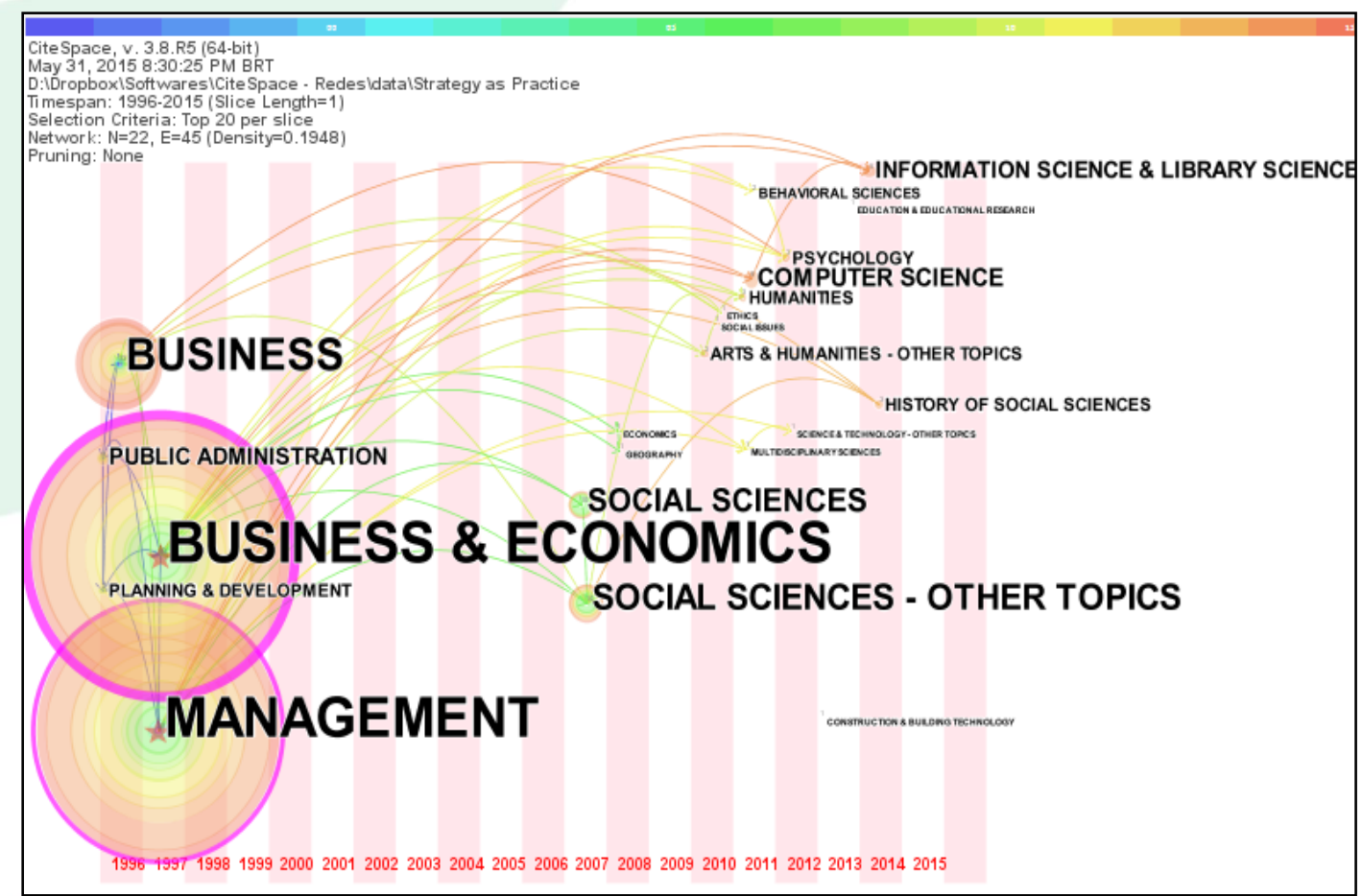

Figura 6 - Rede de áreas do conhecimento Fonte: Elaborado pelos autores.

5.2 Research Front e Pontos de Inflexão do campo de SAP

Na Figura 7 é trazida a rede de co-citações, indicando as obras mais citadas, bem como aquelas que representam pontos de inflexão da produção científica, ou seja, demonstram possibilidades de mudança dentro do campo ou demarcam continuações em determinadas temáticas. No layout originado no CiteSpace, os pontos de inflexão são marcados com um círculo roxo.

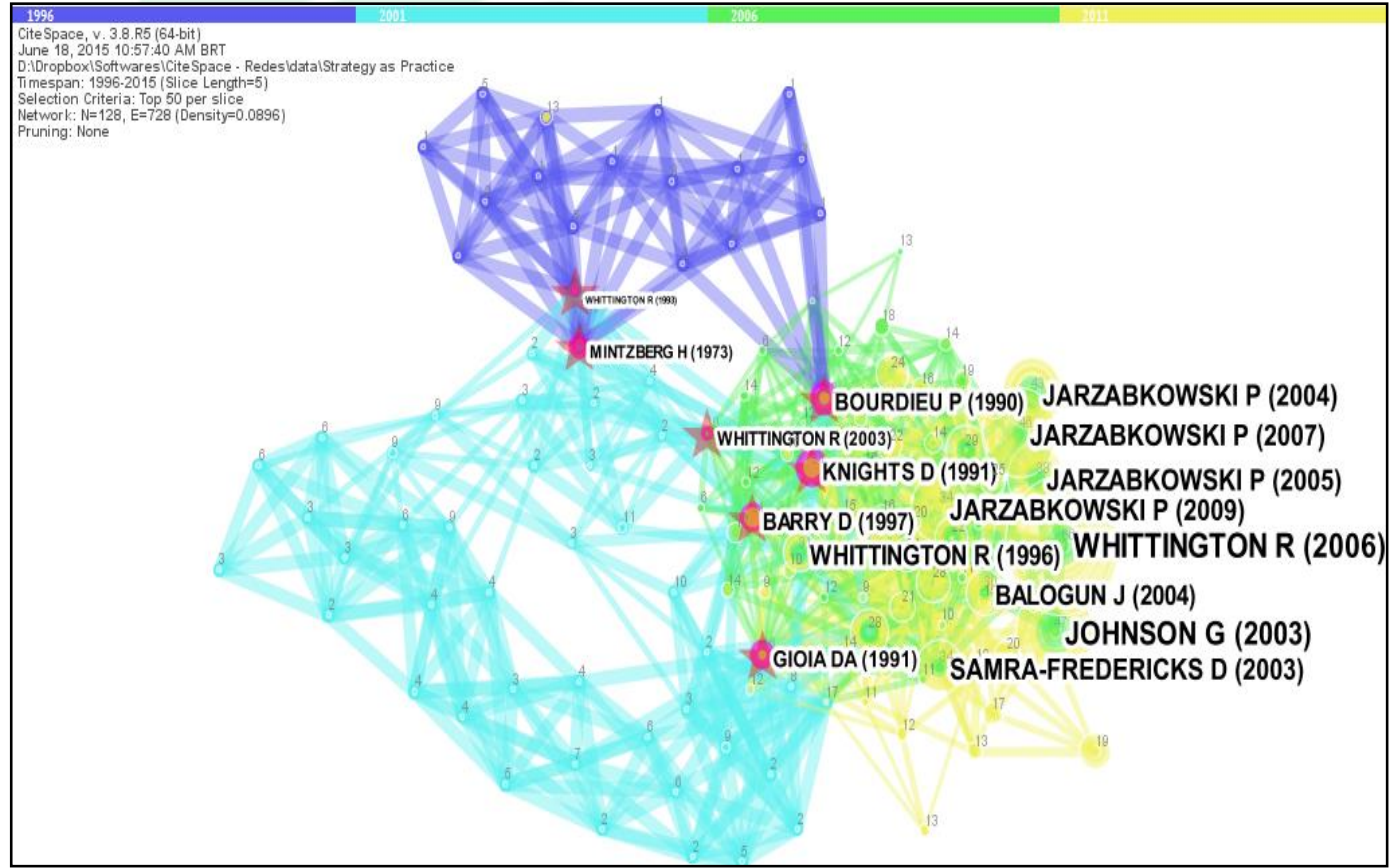

Figura 7 - Rede de co-citações Fonte: Elaborado pelos autores. 
Diferente da Tabela 1, na qual são apresentados os artigos mais citados em Web of Science, no gráfico da Figura 8 são trazidas as citações dos nove artigos mais citados (considerados base intelectual), ano a ano, dentro da rede formada pelos 103 artigos.

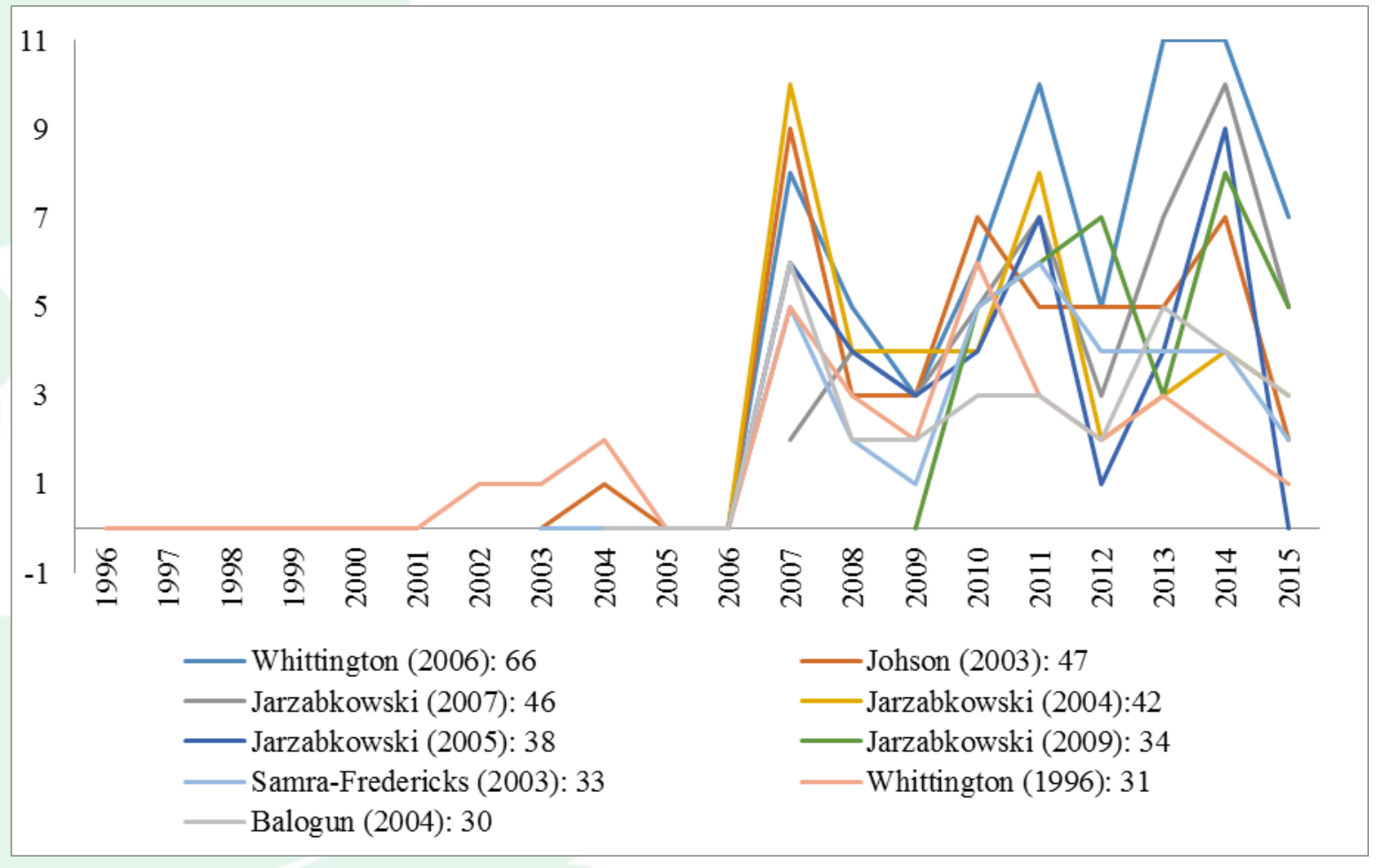

Figura 8 - Citações por ano do research front da rede de co-citações Fonte: Elaborado pelos autores.

Os pontos de inflexão da rede de co-citação gerada são apresentados na Figura 9.

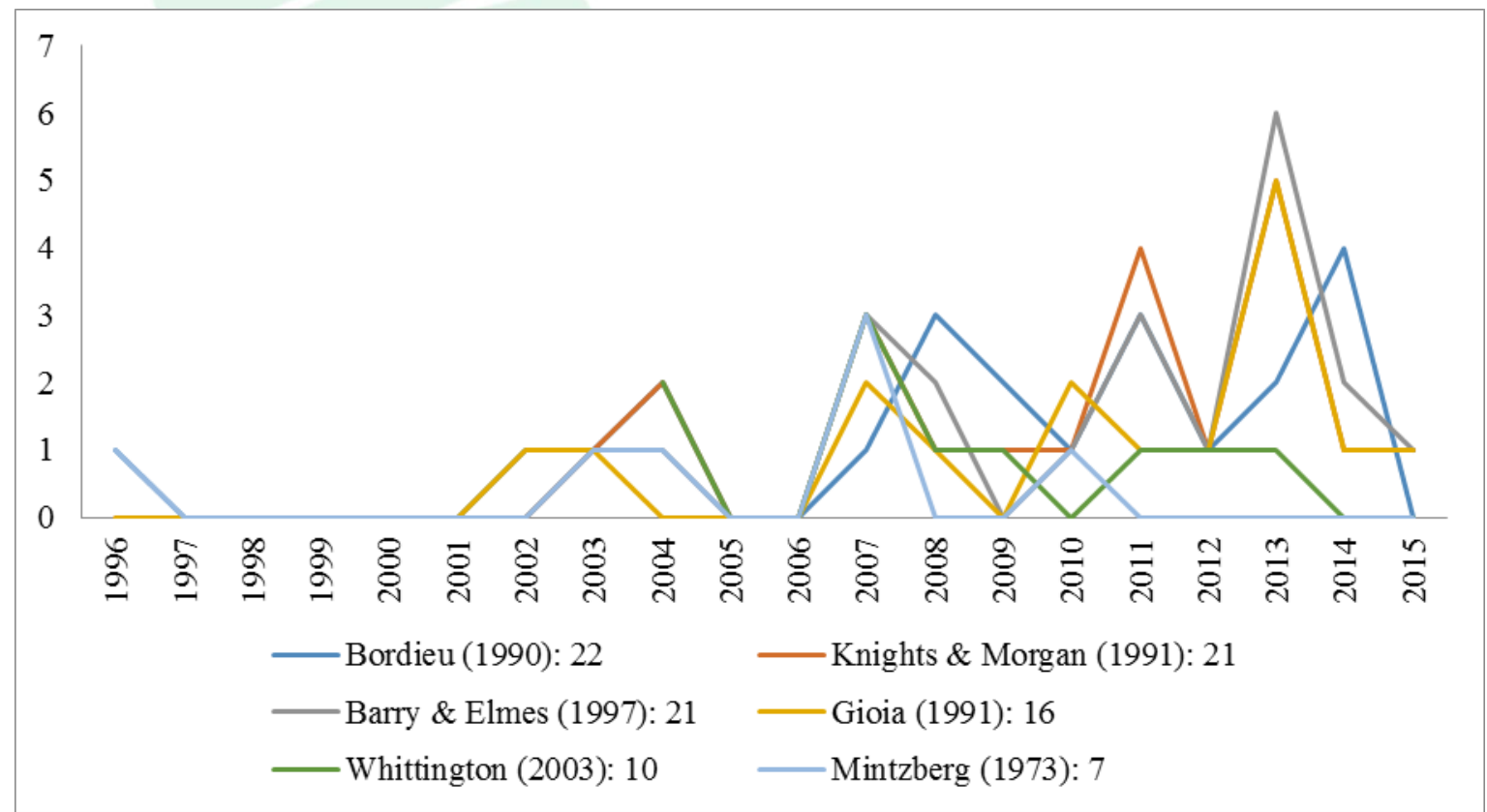

Figura 9 - Citação por ano dos turning points da rede de co-citações. Fonte: Elaborado pelos autores. 
Neste artigo optou-se por verificar a presença das categorias centrais, viradas no campo e de citações de autores da virada prática (tanto para a base intelectual quanto para os pontos de inflexão), assim, recorrendo aos trabalhos de Clegg et al. (2004), Whittington (2006) e Jarzabkowski et al. (2007). Para tanto foi utilizado o Nvivo 10 para a verificação da frequência dos termos e facilitar a análise dos textos.

\section{DISCUSSÃ̃}

A partir dos resultados da seção anterior é possível discutir a fundo o research front e os turning points, evidenciando suas contribuições principais e categorias utilizadas, assim como fazer uma síntese das discussões aliada aos resultados encontrados, dessa forma a discussão é dividida em duas partes: (a) análise do research front e turning points; e (b) síntese dos resultados.

\subsection{Análise do research front e turning points}

Quanto à base intelectual da rede criada, é importante trazer inicialmente o texto seminal do campo, Strategy as Practice, de Whittington (1996), no qual o autor destaca a existência de grande diversidade nos estudos de estratégia, buscando espaço para uma perspectiva diferenciada. Em sua discussão inicial, Whittington (1996) apresenta 4 perspectivas do estudo da estratégia, desenvolvidas a partir da década de 70 , divididas entre níveis de análise (organização ou gerentes) e entre as questões "onde?" e "como?". A perspectiva da prática está no nível da gerência e da questão "como" e utiliza de elementos da tradição processual, mesmo que se distanciando dessa por considerar a importância da competência prática do gerente como um estrategista.

A agenda proposta incialmente por Whittington (1996) envolve pesquisar o trabalho estratégico e como os gerentes aprendem a fazê-lo. Em seu outro trabalho presente na base intelectual, Completting the practice turn in strategy research (o texto mais citado na rede de co-citação), Whittington (2006) busca 'completar a virada prática', superando perspectivas focadas em atividade estratégica no nível intra-organizacional ou dos efeitos dessa atividade em nível extraorganizacional. Conforme argumentado nos fundamentos teóricos, Whittington (2006) utiliza de um framework que envolve três conceitos centrais: práxis, prática e praticantes.

De forma semelhante à Whittington (2006), Jarzabkowski et al. (2007, p. 7), em Strategizing: the chalenges of a practice perspective, trazem questões centrais para a realização de pesquisas nesse campo: "What is strategy? Who is a strategist? What do strategists do? What does an analysis of strategists and their doings explain? How can existing organization and social theory inform an analysis of strategy-as- practice?" Para auxiliar essas respostas, os autores se baseiam no framework de Whittington (2006), destacando a importância da práxis, práticas e praticantes.

É notável a presença dos textos de Paula Jarzabkowski na base intelectual: estão presentes na base os artigos Jarzabkowski (2004); Jarzabkowski e Kaplan (2010); Jarzabkowski, Balogun e Seidl (2007); e Jarzabkowski e Balogun (2009). Em seu artigo Strategy as practice: recursiveness, adaptation, and practices-in-use, Jarzabkowski (2004) traça um framework a fim de explicar as práticas recursivas e adaptativas. A autora apresenta que recursividade e adaptação são dois temas chave para o estudo da prática em organizações: a tensão entre essas duas categorias, considerando até em que nível deve-se promover mudança ou estabilidade é um desafio presente.

Para o desenvolvimento de sua fundação teórica, Jarzabkowski recorre à Teoria da Estruturação de Giddens, aos conceitos de habitus de Bourdieu, social becoming de Sztompka e comunidades de prática, de Brown e Duguid. Adiante, a autora busca desenvolver um entendimento mais holístico da natureza da estratégia como prática. Dado o foco em recursividade e adaptação, a categoria 'instituições' está presente em todo o texto, ao tratar da institucionalização das práticas e das estruturas institucionais sociais.

Já em Taking "strategy as practice" across the atlantic, Jarzabkowski e Kaplan (2010) se propõem a discutir a demorada ida da estratégia como prática para os EUA, enquanto outras ideias de administração estratégica 'viajaram' muito mais rápido dos EUA para a Europa. Como causas dessa dificuldade, as autoras apresentam dois motivos centrais: (1) a pesquisa em SAP é predominantemente qualitativa, enquanto os revisores dos mais importantes periódicos norte americanos sobre estratégia utilizam métodos quantitativos; (2) alguns revisores e editores resistem à mudanças pretendidas pelos autores de SAP, desde uma negação de não trazer novo entendimento sobre estratégia, tendo em vista a existência da tradição processual da estratégia nos EUA, até uma crítica ao sttrategizing. Como saídas apontadas, tem-se a necessidade de identificar e legitimizar resultados da pesquisa em SAP, e não apenas publicar, mas também realizar pesquisas em organizações dos EUA. Além disso, a SAP, colocada como contraparte de estudos tradicionais de estratégia, ainda não foi utilizada em ensaios que versem sobre as possibilidades de uma 'lente prática' poder explicar inconsistências no mainstream da estratégia.

Em The practice and process of delivering integration through strategic planning, Jarzabkowski e Balogun (2009) investigam como os encontros de planejamento estratégico podem favorecer a participação e comunicação entre atores com diferentes interesses e também maior compromisso com objetivos 
estratégicos comuns. As autoras fazem uma discussão sobre planejamento estratégico, fazer estratégico e atividade política para embasar o estudo. Considerando as interações sociais e que o planejamento estratégico é uma atividade política, destaca-se a ênfase no 'poder', tanto na formação de coalizões para aumento de influência, quanto nas diferenças evidenciadas nas percepções dos participantes sobre posição que ocupam no planejamento estratégico.

Nos textos de Jarzabkowski, nota-se a presença de artigos aqui apresentados como pontos de inflexão da produção científica, como Knights e Morgan (1991), Barry e Elmes (1997) e Whittington (2003).

Em outra direção, Samra-Fredericks (2003), em Strategizing as lived experience and strategists' everyday efforts to shape strategic direction, busca uma abordagem multidisciplinar, recorrendo à etnografia e etnometodologia para pesquisar strategistis-at-work, em um estudo de caso realizado em uma indústria. A autora destaca a importância da 'linguagem', uma vez que é através de conversações que os estrategistas negociam e estabelecem sentidos, articulam percepções e legitimam julgamentos individuais e coletivos. Assim, "[...] we need to develop a more theoretically incisive understanding of the importance of language use or talk for constituting actions (shaping strategic direction) and more generally, for socially constructing 'organization'/social order" (Samra-Fredericks, 2003, pp. 142-143).

No último texto da base intelectual selecionada, Balogun e Johnson (2004), em Organizational restructuring and middle manager sensemaking, realizam um estudo qualitativo e longitudinal do papel de gerentes médios em um processo (imposto) de mudança. Para embasar o estudo, os autores tratam dos conceitos de sensemaking, cognição e mudança. Os principais achados relacionam-se a necessidade de entendimento das reações dos recipientes da mudança e, no caso dos gerentes médios estudados, recipientes e agentes da mudança, evidenciando que em grandes empresas, ainda mais naquelas dispersas geograficamente, a alta gerência ou diretoria tornam-se 'fantasmas' na criação de sentido da gerência média, influenciando significados organizacionais por meio da presença de suas ações e palavras em estórias e rumores.

Assim, após a discussão dos trabalhos que compõem a base intelectual do campo, destacam-se como categorias analíticas importantes 'poder', 'instituições' e 'linguagem', enquanto 'identidade' e 'materialidade' são citadas en passant. Já 'atores não humanos' não está presente em nenhum dos artigos da base intelectual selecionada.

Por sua vez, os 4 artigos considerados pontos de inflexão na análise realizada no CiteSpace trazem importantes reflexões adicionais às considerações sobre a base intelectual. Dentre eles está um ensaio editorial escrito para a Strategic Organization, intitulado The work of strategizing and organizing: for a practice perspective, no qual Whittington (2003. p. 117) traz questões de pesquisa relevantes a fim de evidenciar a importância do strategizing. Whittington (2003) também apresenta a importância da virada prática nas ciências sociais e, posteriormente, nos estudos de estratégia.

Os outros três pontos de inflexão não são artigos do campo de SAP, embora sejam razoavelmente citados no campo, principalmente por artigos da base intelectual. Dois dos artigos são anteriores ao artigo seminal de Whittington (1996) - Knights e Morgan (1991) e Gioia e Chittipeddi (1991) - e outro publicado um ano depois, Barry e Elmes (1997).

Knights e Morgan (1991) discorrem sobre discurso estratégico, baseados em Michel Foucault. Os autores desenvolvem uma perspectiva que consideram diferenciada daquelas que veem a estratégia como um conjunto de técnicas racionais para administrar negócios complexos e também daquela que considera o caráter político dos processos estratégicos desenvolvendo modelos racionais para a mudança organizacional. Os autores relatam uma tendência de naturalizar o discurso da estratégia corporativa, desconsiderando sua característica problemática para a vida organizacional. Para desenvolver o conceito de discurso estratégico, Knights e Morgan (1991), utilizam os conceitos de discurso, genealogia e poder em Foucault. Em termos gerais, eles entendem o discurso como "[...] a set of ideas and practices which condition our ways of relating to, and acting upon, particular phenomena" (Knights, \& Morgan, 1991, p. 253). O conceito de genealogia é utilizado para afirmar que discursos são fenômenos historicamente construídos. A essa discussão, os autores acrescentam a estratégia coorporativa, para então verificar os efeitos do poder do discurso.

Já Gioia e Chittipeddi (1991), em Sensemaking and sensegiving in strategic initiaton, realizam um estudo etnográfico do começo de um esforço de mudança estratégica em uma universidade pública, utilizando o par conceitual sensegiving e sensemaking ao tratar da mudança iniciada pelo novo presidente da organização. Sensemaking e sensegiving correspondem, na análise feita pelos autores, a períodos dominados por 'entendimento' e 'influência', respectivamente, assim como 'cognição' e 'ação', de modo que possibilita uma visão diferenciada do papel da alta gerência na mudança estratégica: comparando-a, metaforicamente, a arquitetos, assimiladores e facilitadores da mudança, envolvendo atividades simultaneamente simbólicas e substantivas.

Por fim, Barry e Elmes (1997), em Strategy retold: toward a narrative view of strategic discourse, propõem uma virada narrativa na estratégia, ao considerar a administração estratégica como uma ficção, não em caráter de falsidade, mas que é criada, construída. Para os autores, a estratégia vista como uma narrativa destaca seu caráter discursivo e social, ligando-a aos contextos histórico e cultural. A narrativa é uma forma de criar sentido, as estórias 
Desvelando o Campo da Estratégia como Prática e suas Relações

organizacionais devem ser persuasivas e visar à reprodução, evitando assim noções simplistas e unitaristas de sucesso estratégico, sendo, em última instância, uma construção social. Apoiados em autores do Formalismo russo, principalmente Victor Shklovsky, Barry e Elmes (1997) entendem que um narrador eficaz deve conseguir dois resultados: credibilidade e estranhamento, em uma relação dialética. Barry e Elmes (1997) consideram, por fim, que a perspectiva da estratégia como estória (strategyas-story) pode oferecer alternativas para o entendimento do sucesso organizacional, aliados a necessidades narrativas. A perspectiva narrativa pode trazer contribuições quando se estuda o poder a e a política da estratégia.

Os pontos de inflexão estudados denotam a importância da comunicação e da linguagem para o campo de SAP e tratam das viradas prática e narrativa. 'Poder', 'identidade' e 'instituições' foram as categorias mais recorrentes. Percebe-se que a estratégia como prática discursiva é um ponto de mudança no campo, notando-se que aspectos comunicacionais tem se tornado mais presentes nas publicações, como em Samra-Fredericks (2003).

Analisados em conjunto, base intelectual, pontos de inflexão e artigos da rede de co-citação criada e tomando como base a agenda sugerida por Clegg et al. (2004), percebe-se uma predominância das categorias poder e instituições, enquanto materialidade e identidade são pouco trabalhadas. Atores não humanos é uma categoria não discutida na rede de cocitações dos artigos selecionados, indicando uma lacuna na produção. Contudo, convém ressaltar a publicação de um número especial do periódico British Journal of Management, volume 26, no ano de 2015, voltado para a discussões em torno da materialidade (fazendo referências à categoria de atores nãohumanos) envolvida no fazer estratégia, inserida no escopo da SAP e mostrando a preocupação de pesquisadores em atender tal chamada (WHITTINGTON, 2015). Da mesma forma, práxis, prática e praticantes são categorias ausentes nos pontos de inflexão e pouco citadas na base intelectual, com exceção dos dois textos que trabalham com elas, a saber, Whittington (2006) e Jarzabkowski et al. (2007).

Cabe ainda destacar as categorias com nenhuma ou baixíssima ocorrência, dentre o research front e pontos de inflexão: materialidade, ética, identidade e atores não-humanos, que demonstram que as discussões centrais do campo ainda desconsideram boa parte do chamado de Clegg et al (2004).

$\mathrm{Na}$ Tabela 5 é apresentada uma síntese das ocorrências das categorias analisadas e também dos autores da virada prática, feita a partir de análises no NVivo 10, as quais serviram de base para a discussão desse tópico.

Tabela 5 - Categorias e de atores da virada prática - base intelectual e pontos de inflexão

\begin{tabular}{|c|c|c|c|c|c|c|c|c|c|c|c|c|c|c|}
\hline \multirow[b]{2}{*}{$\begin{array}{c}\text { Textos: total de citações na } \\
\text { rede }\end{array}$} & & \multicolumn{9}{|c|}{ Categorias } & \multicolumn{4}{|c|}{ Autores } \\
\hline & कृ & 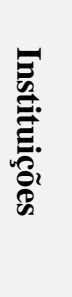 & 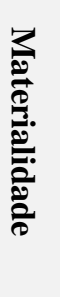 & 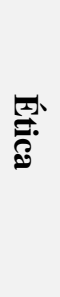 & 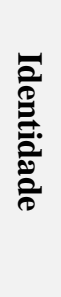 & 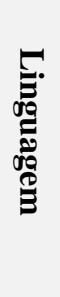 & 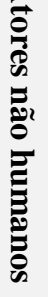 & D. & 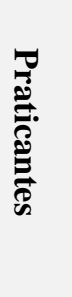 & 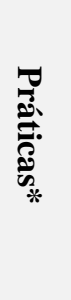 & $\frac{\Omega}{0}$ & 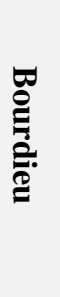 & 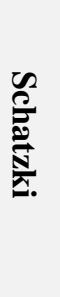 & 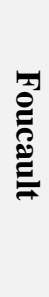 \\
\hline \multicolumn{15}{|l|}{ Base Intelectual } \\
\hline Whittington (2006): 66 & 6 & 12 & 0 & 0 & 2 & 2 & 0 & 65 & 73 & 140 & 11 & 11 & 5 & 5 \\
\hline Johnson et al. (2003): 47 & 2 & 23 & 0 & 0 & 0 & 0 & 0 & 0 & 9 & 19 & 0 & 0 & 0 & 0 \\
\hline $\begin{array}{l}\text { Jarzabkowski et al. (2007): } \\
46\end{array}$ & 4 & 11 & 1 & 0 & 13 & 2 & 0 & 31 & 43 & 88 & 3 & 3 & 4 & 0 \\
\hline Jarzabkowski (2004):42 & 14 & 64 & 3 & 0 & 8 & 2 & 0 & 0 & 6 & 129 & 12 & 12 & 0 & 0 \\
\hline $\begin{array}{c}\text { Jarzabkowski \& Kaplan } \\
\text { (2010): } 38\end{array}$ & 2 & 6 & 4 & 0 & 3 & 0 & 0 & 0 & 8 & 43 & 3 & 3 & 5 & 0 \\
\hline $\begin{array}{c}\text { Jarzabkowski \& Balogun } \\
\text { (2009): } 34\end{array}$ & 41 & 1 & 3 & 0 & 2 & 2 & 0 & 0 & 0 & 6 & 0 & 0 & 0 & 0 \\
\hline Samra-Fredericks (2003): 33 & 5 & 10 & 5 & 0 & 5 & 26 & 0 & 0 & 4 & 8 & 7 & 7 & 0 & 1 \\
\hline Whittington (1996): 31 & 0 & 1 & 0 & 0 & 0 & 0 & 0 & 0 & 15 & 8 & 0 & 0 & 0 & 0 \\
\hline $\begin{array}{l}\text { Balogun \& Johnson (2004): } \\
30\end{array}$ & 5 & 3 & 0 & 0 & 4 & 4 & 0 & 0 & 1 & 11 & 0 & 0 & 0 & 0 \\
\hline Total & 79 & 131 & 16 & 0 & 37 & 38 & 0 & 96 & 159 & 452 & 36 & 36 & 14 & 6 \\
\hline Pontos de Inflexão** & & & & & & & & & & & & & & \\
\hline
\end{tabular}


Desvelando o Campo da Estratégia como Prática e suas Relações

\begin{tabular}{|c|c|c|c|c|c|c|c|c|c|c|c|c|c|c|}
\hline $\begin{array}{l}\text { Knights \& Morgan (1991): } \\
21\end{array}$ & 81 & 14 & 3 & 0 & 9 & 4 & 0 & 0 & 8 & 25 & 6 & 0 & 0 & 10 \\
\hline Barry \& Elmes (1997): 21 & 6 & 1 & 5 & 0 & 7 & 7 & 0 & 0 & 3 & 2 & 0 & 0 & 0 & 0 \\
\hline Gioia (1991): 16 & 3 & 8 & 1 & 0 & 1 & 1 & 0 & 0 & 0 & 1 & 0 & 0 & 0 & 0 \\
\hline Whittington (2003): 10 & 0 & 0 & 0 & 0 & 3 & 1 & 0 & 0 & 2 & 14 & 0 & 0 & 0 & 0 \\
\hline Total & 90 & 23 & 9 & 0 & 20 & 13 & 0 & 0 & 13 & 42 & 6 & 0 & 0 & 10 \\
\hline $\begin{array}{l}\text { *Retiradas } \\
* * \text { Apenas artigos, os liv } \\
\text { fato de não aderirem à pro }\end{array}$ & $\begin{array}{l}\text { con } \\
\text { s de }\end{array}$ & gem & & & $\mathrm{de}$ & rate & 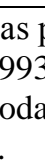 & 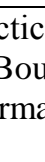 & e"s & $\begin{array}{l}\text { tegy } \\
\text { 90) }\end{array}$ & 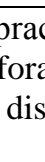 & 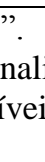 & & $\begin{array}{l}\text { lo } \\
\text { ores }\end{array}$ \\
\hline
\end{tabular}

Fonte: Elaborado pelos autores.

\subsection{Síntese dos Resultados}

Com base nos resultados apresentados na seção anterior, é possível destacar resultados próximos com outros trabalhos de revisão do campo de estudo da Estratégia como prática. No que se refere ao desenvolvimento quantitativo da abordagem, foram percebidas, de modo geral, as mesmas tendências e lacunas temporais evidenciadas por Walter \& Augusto (2011; 2012), Walter et al. (2012) e Okayama et al. (2014), demonstrando o crescimento do campo, em número de artigos e citações, sobretudo após o ano de 2007.

Os resultados demonstram a predominância de certos autores e suas redes de coautorias, destacando Paula Jarzabkowski e Richard Whittington, bem como os países com maior produtividade (Inglaterra, Canáda, Austrália, etc.) também evidenciados em todos os trabalhos apresentados no Quadro 3. Além disso, percebeu-se a concentração dos artigos em periódicos caracterizados dentro do campo dos Estudos Organizacionais em detrimento de revistas especializadas em Administração Estratégica. Este trabalho evidencia de forma inédita o movimento de expansão da abordagem, principalmente nos últimos 5 anos para áreas da ciência como ciência da informação e computação, artes e outros tópicos dentro das ciências humanas.

Ressalta-se que a principal contribuição deste estudo ao campo e, comparativamente, à outros artigos de revisão no âmbito da Estratégia como Prática esteja na apresentação da base intelectual do campo e dos trabalhos tidos como pontos de inflexão para o desenvolvimento da abordagem. A partir desta análise foi possível observar que dentre os pontos de inflexão, estão poucos autores que representam a virada prática, de modo que a grande quantidade de citações a autores como Pierre Bourdieu, Anthony Giddens e Michel Foucault não compreendem, em boa parte dos casos, uma discussão aprofundada de seu pensamento, sendo citados apenas de forma en passant como meio para a legitimação de suas contribuições para o desenvolvimento da perspectiva da Estratégia como Prática, corroborando a proposição de Maciel \& Augusto (2013) de que a virada prática ainda pode ser melhor explorada.

\section{CONSIDERAÇÕES FINAIS}

Inicialmente, percebe-se o crescimento do campo de estudos na perspectiva da SAP, sobretudo após o ano 2007, corroborando com outros trabalhos de revisão tais como Walter e Augusto (2011, 2012), Walter et al. (2012) e Okayama et al. (2014). Os resultados indicam também uma predominância das categorias poder e instituições, enquanto linguagem, apesar de constar em vários artigos, possui baixa média de ocorrência. Identidade e atores não humanos são pouco pesquisadas.

Como limitações de pesquisa, duas principais podem ser elencadas: (1) a limitação de usar a Core Collection da Web of Science, que reduz consideravelmente a quantidade de artigos (a busca em todas as coleções retorna 148 artigos, enquanto a busca na Core Collection retorna 103), essa limitação se justifica pelo fato que as demais bases não geram arquivos de texto compatíveis com o software CiteSpace, essencial para o desenvolvimento dessa revisão. (2) Não foi possível analisar no Nvivo 10 três pontos de inflexão apontados nos resultados Mintzberg (1973), Bourdieu (1990) e Whittington (1993), por serem livros não disponíveis aos autores. No tópico 4.2, buscou-se minimizar tal limitação ao trazer discussões semelhantes e textos que os citam.

Como contribuições

principais, metodologicamente, identifica-se o uso do software CiteSpace e do referencial de base intelectual, research front e ponto de inflexão, abordados por Chen (2006), bem como a sistematização do procedimento realizado, tornando possível sua reprodução futura ou para outros campos. Considerando a contribuição para a perspectiva de SAP, tem-se a discussão das categorias centrais e periféricas, bem como dos textos que são mais citados dentro da rede de co-citação criada, indicando quem os autores mais citam.

Por último, ao refletir-se sobre uma agenda de pesquisa, alguns caminhos podem ser trilhados a partir desse trabalho: (i) expandir a base intelectual do campo, com artigos com um número menor de citações na rede de co-citações, mas que ainda são significativos para o campo; (ii) verificar a existência de outros 
artigos dos autores tidos como referência para o campo, como Whittington e Jarzabkowski, que não foram contemplados nesse estudo; e (iii) verificar a presença e relevância da perspectiva da estratégia como prática na área geral de administração, comparando-a a outras perspectivas e verificando possíveis aproximações.

\section{REFERÊNCIAS}

Araújo, C. A. (2006). Bibliometria: evolução história e questões atuais. Em Questão, 12(1), 11-32.

Balogun, J., \& Johnson, G. (2004). Organizational Restructuring and Middle Manager Sensemaking. The Academy of Management Journal, 47(4), 523549.

Barry, D., \& Elmes M. (1997). Strategy retold: Toward a narrative view of strategic discourse. Academy of Management Review, 22(2), 429-452.

Botelho, L. L. R., Cunha, C. C. A., Macedo, M. (2011). O método da revisão integrativa nos estudos organizacionais. Gestão e Sociedade, 5(11), 121136.

Bourdieu, P. (1990). The Logic of Practice. Cambridge: Polity.

Brito, M. J., Brito, V. G. P., Borges, A. F., \& Andrade, L. P. (2014, setembro). Proposta teóricometodológica para o estudo da Estratégia como Prática Social: uma abordagem construcionista. Anais do Encontro Nacional da Associação Nacional de Pós-Graduação e Pesquisa em Administração, Rio de Janeiro, RJ, Brasil, 38.

Canhada, D. I. D., \& Rese, N. (2009). Contribuições da 'estratégia como prática' ao pensamento em estratégia. REBRAE, 2(3), 273-289.

Chen, C. (2006). CiteSpace II: Detecting and visualizing emerging trends and transient patterns in scientific literature. Journal of the American Society for Information Science and Technology, 57(3), 359-377.

Chia, R. (2004). Strategy-as-practice: reflections on the research agenda, European Management Review. 1(1), 29-34.

Clegg, S., \& Carter, C. and Kornberger, M. (2004). Get up, I feel like being a strategy machine. European Management Review, 1(1), 21-28.

Figueiredo, N. (1990). Da importância dos artigos de revisão da literatura. Revista Brasileira de Biblioteconomia e Documentação, 23(1), 131-135.
Gioia, D. A., \& Chittipeddi, K. (1991). Sensemaking and sensegiving in strategic change initiation, Strategic Management Journal. 12(6), 433-448.

Golsorkhi, D., Rouleau, L., Seidl, D., \& Vaara, E. (2010). Cambridge Handbook of Strategy as Practice. Cambridge: University Press.

Harwood, S. A. (2011). Can a cybernetic lens contribute to the business strategy domain? Kybernetes, 40(3), 507-527.

Jarzabkowski, P., \& Wilson, D.C. (2002). Top teams and strategy in a UK university. Journal of Management Studies, 39, 355-387.

Jarzabkowski, P. (2003), Strategic Practices: An Activity Theory Perspective on Continuity and Change. Journal of Management Studies, 40(1), 2355.

Jarzabkowski, P. (2005). Strategy as Practice: An Activity Based Approach. London: Sage.

Jarzabkowski, P. (2004). "Strategy as practice: recursiveness, adaptation, and practices-in-use. Organization Studies, 25(4), 529-560.

Jarzabkowski, P., Balogun, J., \& Seidl, D. (2007). Strategizing: The challenges of a practice perspective. Human Relations, 60(1), 5-27.

Jarzabkowski, P., \& Spee, A. P. (2009). Strategy-aspractice: A review and future directions for the field. International Journal of Management Reviews, 11(1), 69-95.

Jarzabkowski, P., \& Balogun, J. (2009). The Practice and Process of Delivering Integration through Strategic Planning. Journal of Management Studies, 46(8), 1255-1288.

Jarzabkowski, P., \& Kaplan, S (2010), Taking 'strategy-as-practice' across the Atlantic. In Baum, J. A. C., \& Lampel, J. (Ed.). The Globalization of Strategy Research (27, Chap. 4, pp. 51-71). London: Emerald Group Publishing Limited.

Johnson, G., Melin, L., \& Whittington, R. (2003). Micro strategy and strategizing: Towards an activity-based view. Journal of Management Studies, 40(1), 3-22.

Johnson, G., Langley, A., Melin, L., \& Whittington, R. (2007). Strategy as practice: research directions and resources. Cambridge: Cambridge University Press.

Knights, D., \& Morgan, G. (1991). Strategic discourse and subjectivity: Towards a critical analysis of 
Service Research Methodology: From Case Study Research to Case Theory

corporate strategy in organizations. Organization Studies, 12(3), 251-273.

Maciel, C. D. O. \& Augusto, P. O. M. (2013). Análise da produção científica em estratégia como prática. Revista Brasileira de Estratégia, 7(2), p. 191-204.

Maia, J. L., Serio, L. C., \& Alves Filho, A. G. (2015). Almost Two Decades After: A Bibliometric effort to Map Research on Strategy as Practice using two Data Sources. European Journal of Economics, Finance and Administrative Sciences, 73, 7-31.

Mancini, M. C.; Sampaio, R. F. (2006). Quando o objeto de estudo é a literatura: estudos de revisão. Revista Brasileira de Fisioterapia, 10(4).

McKiernan, P., \& Carter, C. The millennium nexus: Strategic management at the cross-roads. European Management Review, 1(1), 3-13.

Mintzberg, H. (1973). The nature of managerial work. New York: Harper Collins Publishers.

Moreno, J. L. (1972). Fundamentos de la Sociometría. Buenos Aires: Paidós.

Okayama, E. Y., Gag, M., \& Oliveira Junior, P. F. P. (2014). Análise da produção científica em estratégia como prática. Revista Brasileira de Estratégia, 7(2), 191-204.

Paiva, A. L.; Alcântara, V. C.; Andrade, L. F.; Tonelli, D. F. \& Brito, M. J. (2015) Traços da virada linguística na estratégia como prática: uma revisão de escopo. In: XVIII SEMEAD - Seminários em Administração, São Paulo, 2015. Anais... São Paulo: FEA/USP.

Pinto, C. F; Serra, F. R. \& Ferreira, M. P. (2014). A Bibliometric Study on Culture Research in International Business. Brazilian Administration Review, 11(3), 340-363.

Rumrill, P. D.; Fitzgerald, S. M. \& Merchant, W. R. (2010) Using scoping literature reviews as a means of understanding and interpreting existing literature. Work, 35(3), 399-404.

Rusko, R. (2013). Out-of-the-box? The state of the academic discussions about strategies and strategy work. Problems and Perspectives in Management, 11(4), p. 133-146.

Samra-Fredericks, D. (2003). Strategizing as lived experience and strategists' everyday efforts to shape strategic direction. Journal of Management Studies, 40, 57-82.

Seidl, D. \& Whittington, R. (2014) Enlarging the Strategy-as-Practice Research Agenda: Towards Taller and Flatter Ontologies. Organization Studies, Perspectives, p. 1-15.

Vaara, E., \& Whittington, R. (2012). Strategy-asPractice: Taking Social Practices Seriously. The Academy of Management Annals, 6(1), 285-336.

Walter, S. A., \& Augusto, P. O. M. (2011). A institucionalização da estratégia como prática nos estudos organizacionais. Revista de Administração, 46(4), 392-406.

Walter, S. A., \& Augusto, P. O. M. (2012). Prática estratégica e strategizing: mapeamento dos delineamentos metodológicos empregados em estratégia como prática. Revista Eletrônica de Ciência Administrativa (RECADM), 11(1), 131142.

Walter, S. A., Bachl, T. M., \& Barbosa, F. (2012). Estratégia como prática: análise longitudinal por meio de bibliometria e sociometria. Revista Brasileira de Estratégia, 5(3), 302-327.

Whittington, R. (1993). What is strategy... And does it matter? London: Routledge.

Whittington, R (1996). Strategy as practice. Long Range Planning, 29(5), 731-735.

Whittington, R. (2003). The work of strategizing and organizing: For a practice perspective. Strategic Organization, 1, 119-27.

Whittington, R. (2006). Completing the practice turn in strategy research. Organization Studies, 27(5), 613634.

Whittington, R. (2015). The massification of strategy. British Journal of Management, 26(special issue), 13-16. 